\title{
Evaluation of the EUMETSAT Global AVHRR Wind Product ${ }^{\circ}$
}

\author{
ÁKOS HORVÁTH \\ University of Hamburg, Hamburg, Germany \\ Olivier Hautecoeur \\ EUMETSAT, and Metis GmbH, Darmstadt, Germany \\ RÉGIS BORDE \\ EUMETSAT, Darmstadt, Germany \\ HARTWig DENEKE \\ Leibniz Institute for Tropospheric Research, Leipzig, Germany \\ STEFAN A. BUEHLER \\ University of Hamburg, Hamburg, Germany
}

(Manuscript received 3 March 2017, in final form 20 June 2017)

\begin{abstract}
The European Organisation for the Exploitation of Meteorological Satellites (EUMETSAT) $M e t O p-A$ and $M e t O p-B$ satellites fly in the same polar orbit with a $180^{\circ}$ phase difference, which enables the global retrieval of atmospheric motion vectors (AMVs, or "winds") by tracking clouds in a pair of Advanced Very High Resolution Radiometer (AVHRR) infrared-window-channel images taken successively by the tandem platforms within their swath overlap area. This novel global wind product has been operational since 2015. As part of ongoing validation efforts, two months of MetOp global AMVs were compared with a suite of independent wind data, including AMVs from geostationary and polar-orbiter satellites as well as radiosonde and model winds. The performance of the new wind product is generally comparable to that of more established satellite winds. In the tropics, however, high-level MetOp global AMVs show a strong fast speed bias, increased root-mean-square difference, and considerably reduced speed correlation relative to all comparison datasets-an as-yet-unexplained drop in retrieval quality that warrants further investigation. A best-fit wind analysis also indicates that selectively applied height adjustments, such as cloud-base and inversion methods, can be a significant source of discrepancy, leading to very poor height correlation among low-level satellite AMVs. Height assignment is more consistent and better correlated at mid- to high levels, although MetOp heights derived from windowchannel brightness temperatures have a bias toward lower heights because of the lack of semitransparency corrections. Collocated Infrared Atmospheric Sounding Interferometer $\mathrm{CO}_{2}$-slicing heights significantly improve the best-fit height-difference statistics at higher altitudes but are available for only $\sim 5 \%$ of MetOp AMVs.
\end{abstract}

Supplemental information related to this paper is available at the Journals Online website: https://doi.org/10.1175/JAMC-D-170059.s1.

Corresponding author: Ákos Horváth,akos.horvath@unihamburg.de

\section{Introduction}

The European Organisation for the Exploitation of Meteorological Satellites (EUMETSAT) Polar System currently consists of the identical MetOp-A and Met $O p-B$ satellites, which carry the Advanced Very High Resolution Radiometer (AVHRR) imaging 
instrument. The two satellites fly one-half of an orbit apart in the same sun-synchronous low-Earth (polar) orbit (LEO) with a period of $100 \mathrm{~min}$ and an equator crossing time of 0930 local solar time. This coplanar configuration in combination with Earth's rotation over $50 \mathrm{~min}$ produces a minimum imagery overlap between the tandem of approximately one-half of a swath at low latitudes. Atmospheric motion vectors (AMVs) - hereinafter also referred to as "winds" although they are only a proxy measure of air motion - are derived day and night by tracking clouds in $10.8-\mu \mathrm{m}$ infrared (IR) images, utilizing either the swath overlap between consecutive orbits of one of the MetOp satellites or that between the pair. EUMETSAT provides three separate AVHRR wind products that complement its geostationary (GEO) AMVs derived from Meteosat imagery, which are limited by view geometry to areas equatorward of $60^{\circ}$ latitude. The various AVHRR winds are extracted with the same retrieval algorithm but differ in the number of images and satellites used and, therefore, in geographic coverage and total tracking time (Hautecoeur and Borde 2017).

Single-mode polar winds above $50^{\circ}$ latitude are extracted from two consecutive overlapping swaths of the same satellite, generated separately for MetOp-A and MetOp-B. The temporal interval between the two images used for tracking is $\sim 100 \mathrm{~min}$.

Dual-mode global winds are extracted from a pair of images taken successively by the tandem satellites within their swath overlap, an area $\sim 1500 \mathrm{~km}$ wide near the equator and broader at mid- and high latitudes. Two complementary data streams ensure global coverage: one using MetOp-A as the first image of the pair ("A/B winds") and the other using $M e t O p-B$ as the first image ("B/A winds"). The temporal interval between the two images used for tracking is $\sim 50 \mathrm{~min}$.

Triplet-mode polar winds above $50^{\circ}$ latitude are extracted from three consecutive overlapping swaths of the satellite tandem. Again, two complementary data streams are generated: one using $M e t O p-A$ as the first image of the triplet ("A/B/A winds") and the other using $M e t O p-B$ as the first image ("B/A/B winds"). The temporal interval between two consecutive images is $\sim 50 \mathrm{~min} —$ similar to dual mode—and the time period used for tracking is $\sim 100 \mathrm{~min}$ - similar to single mode.

The National Oceanic and Atmospheric Administration (NOAA) was the first to produce operational AMVs from polar-orbiter imagers such as Moderate Resolution Imaging Spectroradiometer (MODIS) on Terra and Aqua, AVHRR on NOAA and MetOp satellites, and most recently the Visible Infrared Imaging Radiometer Suite (VIIRS) on the Suomi National PolarOrbiting Partnership platform, using data either in singleor mixed-satellite mode. Their wind retrieval algorithm was pioneered for MODIS and relies on image triplets for cloud tracking (Key et al. 2003). The primary reason behind using image triplets is to facilitate a temporal consistency test between two intermediate wind vectors derived from two consecutive image pairs, which is the standard practice in GEO AMV quality control (Holmlund et al. 2001). These intermediate vectors are then averaged to obtain the final wind vector. The number of images used, along with orbit inclination and sensor swath width, constrains the size of the overlap region available for cloud tracking. As a result, the coverage of NOAA polar winds is generally limited to latitudes poleward of $65^{\circ}-70^{\circ}$ for single-satellite and $60^{\circ}-65^{\circ}$ for mixed-satellite AMVs. Also, given that the overlap area of the orbits gets narrower with distance away from the poles in the along-track direction, there still exists an AMV-sparse region in the $55^{\circ}-70^{\circ}$ latitude band between the coverage areas of geostationary and polar winds.

Only recently has it become possible to partially fill this data gap with AMVs produced from composite LEO-GEO images (Lazzara et al. 2014) or potentially with Multiangle Imaging Spectroradiometer (MISR) stereo AMVs (Mueller et al. 2017). The innovation of the EUMETSAT single- and dual-mode AVHRR AMVs is to use image pairs rather than triplets for cloud tracking. This approach increases the swath overlap area and allows retrievals down to $50^{\circ}$ latitude for singlemode AMVs and over the entire globe for dual-mode AMVs, further mitigating the high-latitude coverage gap. Added benefits include a shortened total tracking time (50-100 min vs $200 \mathrm{~min}$ for single-satellite MODIS winds) and, as a consequence, reduced tracking noise and decreased product latency. Reliance on a single image pair also leads to loss of the standard temporal consistency test during AMV quality control, however. The EUMETSAT retrieval algorithm compensates for this by additionally performing a reverse pattern match and then evaluating the consistency of the forward- and backward-tracked wind vectors instead.

Triplet-mode AVHRR AMVs, in turn, combine the higher sampling frequency offered by the coplanar tandem configuration with a traditional-image triplet-based retrieval, which allows a true temporal consistency check between intermediate wind vectors. Such a scheme limits the coverage of triplet-mode winds to polar regions, much like single-mode winds, but improves their overall quality.

Hautecoeur and Borde (2017) evaluated the impact of image update frequency and the temporal consistency test on the performance of the different AVHRR winds. All three products showed a similar speed bias of $\pm 0.2 \mathrm{~m} \mathrm{~s}^{-1}$ and root-mean-square difference (RMSD) of $4.5-6.5 \mathrm{~m} \mathrm{~s}^{-1}$ against forecast winds in polar areas. Including the temporal consistency test in quality 
control did slightly reduce the RMSD of triplet-mode AMVs relative to the other two products, albeit at the price of a $30 \%$ decrease in the number of high-quality winds. Triplet- and dual-mode AMVs were found to better characterize the polar jets than did single-mode AMVs, because a shorter time interval and thus smaller horizontal cloud displacement between images increases the maximum retrievable wind speed within the limited overlap area. A shorter temporal interval between images also leads to larger relative speed errors, however. The effect of these trade-offs on overall data quality is not yet clear though and will require further analysis.

This paper focuses on dual-mode global AVHRR AMVs, for they are the truly unique and novel part of the EUMETSAT LEO wind-product suite. In fact, they currently represent the only satellite-wind dataset that offers complete day-night global coverage-although recently upgraded MISR stereo AMVs may provide a complementary source of near-global daylight winds (Mueller et al. 2017). The global AVHRR AMV product became operational in February of 2015 and has been successfully assimilated by the European Centre for Medium-Range Weather Forecasts (ECMWF) and the Fleet Numerical Meteorology and Oceanography Center numerical weather prediction (NWP) models since February of 2016 (Stone et al. 2017). In addition to their role in NWP, these AMVs also hold potential for serving as a common, homogeneous reference in the evaluation of the numerous other satellite-wind datasets, which cover different parts of the globe and are produced with a diverse set of extraction schemes.

Dual-mode global winds are described in detail by Borde et al. (2016), who also performed a preliminary comparison with well-established GEO AMVs from Meteosat-7 and Meteosat-10. The goal of the current study is to extend the evaluation to a significantly larger set of comparison winds comprising GEO AMVs, polar AMVs, and stereo AMVs, as well as radiosonde and model winds. Our validation set in some cases includes winds derived from the same imagery by two independent producers, which enables highlighting differences caused by algorithm specifics. The addition of nonsatellite winds also ensures a more balanced comparison data mix. We aim to establish a basic set of validation statistics against which future upgrades of the global AVHRR AMV product can be appraised.

\section{Data and methods}

\section{a. Datasets}

A two-month dataset of $M e t O p$ A/B dual-mode global AMVs was obtained from the EUMETSAT Earth
Observation Portal (https://eoportal.eumetsat.int/userMgmt/ login.faces;) for June and August of 2015. The analysis period was restricted to boreal summer by the limited availability of operational-quality AMVs at the beginning of our study. These AVHRR winds were produced with version 2.5 of the AMV Product Processing Facility (EUMETSAT 2016), which uses a priori temperature and wind profiles from the ECMWF forecast model. The complementary $\mathrm{A} / \mathrm{B}$ and $\mathrm{B} / \mathrm{A}$ winds exhibit no relative bias and can be considered to be statistically equivalent, showing similar comparison results against forecast winds (EUMETSAT 2015); therefore, we only evaluated the former.

A major part of our validation dataset was obtained from the operational wind archives of the University of Wisconsin-Madison Cooperative Institute for Meteorological Satellite Studies (CIMSS), consisting of Geostationary Operational Environmental Satellite 15 $\left(\right.$ GOES $\left.-15 ; 135^{\circ} \mathrm{W}\right)$, GOES $-13\left(75^{\circ} \mathrm{W}\right)$, Meteosat- $10\left(0^{\circ}\right)$, Meteosat-7 $\left(57^{\circ} \mathrm{E}\right)$, and Multifunctional Transport Satellite 2 (MTSAT-2;145 ${ }^{\circ}$ ) geostationary AMVs as well as MODIS Terra polar-orbiter AMVs.

The CIMSS GEO AMVs are available on a 3-hourly basis and are derived by tracking cloud features across three successive IR images using an algorithm that is practically identical to the operational NOAA AMV code. The interval between images ranges from 15 to 30 min depending on data availability (Wanzong et al. 2014). The derivation of CIMSS GEO AMVs is guided by a priori temperature and wind profiles interpolated from the 6-hourly analysis state of the ECMWF ERA-Interim model.

The CIMSS MODIS Terra polar AMVs are derived separately for the North and South Poles. The retrieval algorithm relies on IR image triplets collected over two orbit periods or $\sim 200 \mathrm{~min}$ (Key et al. 2003). The derivation of MODIS AMVs is guided by a priori temperature and wind profiles interpolated from the 6- and 9-h forecasts from the NOAA Global Forecast System.

AMVs derived from Meteosat-10 and Meteosat-7 IR imagery were also available from EUMETSAT. The EUMETSAT GEO scheme extracts hourly AMVs from four consecutive Meteosat-10 images or three consecutive Meteosat-7 images taken at 15- and 30-min intervals, respectively (Borde et al. 2014).

To round out the GEO wind comparison set, MTSAT-2 and Himawari-8 $\left(141^{\circ} \mathrm{E}\right)$ AMVs from the Japan Meteorological Agency (JMA) were also included. Full-disk heritage MTSAT-2 AMVs are generated every $6 \mathrm{~h}$ from three consecutive images acquired at 15 -min intervals (Oyama 2010; Hayashi 2012); AMVs from the successor Himawari-8 are derived hourly from image triplets obtained by 10-min scans (Shimoji 2014; Bessho et al. 2016). 
Note that for three geostationary imagers our dataset included two separate wind products derived by independent extraction algorithms. These are the CIMSS and EUMETSAT AMVs for Meteosat-7 and Meteosat-10 and the CIMSS and JMA AMVs for MTSAT-2.

We also considered MISR stereo AMVs in the analysis. The purely geometric MISR wind retrieval technique simultaneously determines cloud motion and height by tracking features in a triplet of $0.67-\mu \mathrm{m}$ images acquired at oblique view angles of $70^{\circ}$ and $46^{\circ}$ and at nadir over a 3.5-min period (Horváth and Davies 2001; Mueller et al. 2013). Because the oblique cameras come in symmetric pairs, one pointing ahead of and one pointing behind the single nadir camera, two intermediate vectors can be calculated from forward and aft image triplets, which are then averaged to obtain a final wind vector during a 7-min Terra overpass. The forward-aft vector difference is used as one of the quality-control checks, akin to a standard temporal-consistency test. The MISR stereo AMVs in this study were specifically from the monthly-aggregate Cloud Motion Vector product (MI3MCMVN), version F02_0002, which is available from the NASA Langley Atmospheric Science Data Center.

In addition to satellite-derived AMVs, we also included more traditional wind data in the comparison. Radiosonde observations (raobs) were obtained from NOAA's Integrated Global Radiosonde Archive (IGRA), version 2 (Durre et al. 2006). A total of 437 stations had observations in June and August of 2015 that could be spatially/temporally matched with MetOp. Model winds were obtained from the ECMWF ERA-Interim daily gridded pressure-level reanalysis with a horizontal and temporal resolution of $0.75^{\circ}$ and $6 \mathrm{~h}$.

Note that the satellite-wind products differ not only in temporal sampling but also in spatial resolution of input imagery and in the size and selection of the target box used for feature tracking, as listed in Table 1. Such instrument and processing differences affect the spatial and temporal scales of motion sampled by the various wind products.

Height assignment is another area of discrepancy among satellite-wind products as summarized in Table 2-in addition to being the main source of uncertainty restricting the assimilation of AMVs in NWP (Velden and Bedka 2009). With the exception of Himawari-8 and MISR, the height assignment of AMVs is performed in a stand-alone step by one of three radiometric methods depending on channel availability: IR window, $\mathrm{CO}_{2}$ slicing, or $\mathrm{H}_{2} \mathrm{O}$ intercept (Nieman et al. 1993). Because cloud tracking and height assignment are accomplished separately, the pixels most influencing the former are not necessarily the same as those used for the latter. Some algorithms apply the crosscorrelation contribution (CCC) method to establish a stronger link between the two retrieval steps and calculate an average AMV height that is weighted by the individual pixel contributions to cloud tracking (Borde et al. 2014).

The IR window or equivalent blackbody brightness temperature (EBBT) technique infers cloud brightness temperature from measured $10.8-\mu \mathrm{m}$ radiance and then uses a forecast temperature profile to map from temperature to pressure level. Two possible downward adjustments are sometimes selectively applied to EBBT heights. If the forecast profile indicates a low-level temperature inversion, the AMV height might be set to the bottom of the inversion layer. Another option is to assign AMVs to the pressure level of an estimated cloud-base temperature (Le Marshall et al. 1993).

The EBBT method is reasonably accurate for opaque clouds but is inaccurate for semitransparent or subpixel clouds (Schreiner et al. 2004). The alternative $\mathrm{CO}_{2}$-slicing technique, which works well for both cloud types, determines the measured ratio of cloudy-clear radiance differences between $\mathrm{CO}_{2}$-absorption and IR-window bands and matches this to theoretical ratios calculated for a range of cloud pressures (Menzel et al. 1983). The $\mathrm{H}_{2} \mathrm{O}$-intercept method is conceptually similar but relies on observed and calculated clear/cloudy radiances in $\mathrm{H}_{2} \mathrm{O}$-absorption and IR-window bands (Schmetz et al. 1993). The $\mathrm{CO}_{2}$-slicing and $\mathrm{H}_{2} \mathrm{O}$-intercept techniques do not work well with lowlevel clouds and are therefore reserved for medium- and high-level AMVs above $700 \mathrm{hPa}$ (pressure smaller than or altitude higher than $700 \mathrm{hPa}$ ).

The AVHRR instrument has neither $\mathrm{CO}_{2}$ nor $\mathrm{H}_{2} \mathrm{O}$ channels, but MetOp AMVs can take advantage of collocated Infrared Atmospheric Sounding Interferometer (IASI) measurements. If the center of the tracked cloud feature is inside an IASI footprint, the AMV is assigned to the $\mathrm{CO}_{2}$-slicing height from the EUMETSAT level-2 IASI cloud-top-pressure product, version 6 . Because of the relatively sparse spatial sampling of IASI, only a few percent of MetOp AMVs can use $\mathrm{CO}_{2}$-slicing heights, and the vast majority are assigned to EBBT heights.

The height assignment of Himawari-8 AMVs, in contrast, is a maximum-likelihood-estimation method, which determines the cloud altitude that simultaneously optimizes consistency between observed and simulated radiances and that between observed and forecast winds (Shimoji 2014). The consistency of radiance and motion is evaluated in the $\mathrm{H}_{2} \mathrm{O}$, IR-window, and $\mathrm{CO}_{2}$ channels using a forward radiative transfer model with input temperature, humidity, and wind profiles from the JMA Global Spectral Model. This optimal-estimation technique has an element of data assimilation and explicitly depends on the wind vector obtained in the tracking step. The combination of motion and radiometric information aims to ensure that the tracked feature not 
TABLE 1. Characteristics of the wind datasets.

\begin{tabular}{|c|c|c|c|c|c|}
\hline Dataset & Label & $\begin{array}{l}\text { Nadir pixel } \\
\text { size }(\mathrm{km})\end{array}$ & $\begin{array}{l}\text { Target box } \\
\text { size }\left(\mathrm{km}^{2}\right)\end{array}$ & Image frequency $(\min )$ & $\begin{array}{l}\text { No. of images/total } \\
\text { tracking time (min) }\end{array}$ \\
\hline GOES-15 CIMSS & $\mathrm{G} 15 \mathrm{c}$ & 4 & $60 \times 60$ & $15-30$ & $3 / 30-60$ \\
\hline GOES-13 CIMSS & G13c & 4 & $60 \times 60$ & $15-30$ & $3 / 30-60$ \\
\hline Meteosat-10 CIMSS & M10c & 3 & $60 \times 60$ & 15 & $3 / 30$ \\
\hline Meteosat-10 EUMETSAT & M10e & 3 & $72 \times 72$ & 15 & $4 / 45$ \\
\hline Meteosat-7 CIMSS & $\mathrm{M} 7 \mathrm{c}$ & 5 & $60 \times 60$ & 30 & $3 / 60$ \\
\hline Meteosat-7 EUMETSAT & M7e & 5 & $160 \times 160$ & 30 & $3 / 60$ \\
\hline$M T S A T-2$ CIMSS & MT2c & 4 & $60 \times 60$ & 15 & $3 / 30$ \\
\hline$M T S A T-2$ JMA & MT2j & 4 & $64 \times 64$ & 15 & $3 / 30$ \\
\hline Himawari-8 JMA & $\mathrm{HI} 8 \mathrm{j}$ & 2 & $34 \times 34$ & 10 & $3 / 20$ \\
\hline MODIS Terra CIMSS & MDTc & $2^{\mathrm{a}}$ & $26 \times 26$ & $\sim 100$ & $3 / \sim 200$ \\
\hline MISR & MISR & 0.275 & $17.6 \times 17.6$ & $1.5-2.0$ & $5 / 7$ \\
\hline Global AVHRR EUMETSAT & MetOp & 1 & $30 \times 30$ & $\sim 50$ & $2 / \sim 50$ \\
\hline Raob IGRA & Raob & - & - & - & - \\
\hline ERA-Interim & ERAI & - & - & - & - \\
\hline
\end{tabular}

${ }^{\mathrm{a}}$ Remapped from $1 \mathrm{~km}$.

only fits the forecast wind field but also conforms to modeled cloud radiances.

Unlike radiometric algorithms, the stereoscopic MISR height assignment is independent of the atmospheric temperature and humidity structure and hence requires no a priori forecast data. The need to distinguish parallax from motion, however, introduces a correlation between the errors in retrieved cloud height and along-track wind component (Horváth 2013). For consistency, MISR geometric AMV heights were converted to heightequivalent pressure levels using the ERA-Interim daily geopotential height reanalysis.

There are two commonly employed quality-control metrics for AMVs. The EUMETSAT quality indicator (QI) generally assesses the spatiotemporal coherency of an AMV with its surrounding satellite-wind vectors but optionally can also include a test against forecast wind vectors (Holmlund et al. 2001). An alternative is the CIMSS recursive-filter (RF) method, which is a three-dimensional objective analysis that incorporates comparisons with numerical forecast fields of wind, temperature, and pressure (Velden et al. 1998). The RF scheme has an element of data assimilation and allows readjustment of the initial AMV heights to minimize difference with model information. Our study used the EUMETSAT QI without the forecast test because it is routinely computed for all operational AMVs.

\section{b. Comparison method}

The collocation criteria recommended for AMV validation by the Coordination Group for Meteorological Satellites (CGMS) are horizontal, vertical, and temporal separation less than $150 \mathrm{~km}, 25 \mathrm{hPa}$, and $90 \mathrm{~min}$, respectively, with a direction difference of less than $60^{\circ}$ between wind vectors (Velden and Holmlund 1998). Although these thresholds were defined to ensure matches with sparse radiosonde observations, for consistency we used them to collocate all validation data, including satellite and model winds. When the relatively loose CGMS criteria produced several candidate comparison AMVs, we selected the one that minimized the vector difference with the MetOp AMV. The choice of the comparison AMV somewhat influences the difference statistics, especially relative to the sparse raobs

TABLE 2. Radiometric height assignment scheme characteristics.

\begin{tabular}{|c|c|c|c|c|}
\hline Dataset & Semitransparency method & Inversion method & Cloud-base-height method & CCC method \\
\hline GEO CIMSS & $\mathrm{H}_{2} \mathrm{O}$ intercept or $\mathrm{CO}_{2}$ slicing & Yes & Yes & No \\
\hline MODIS Terra CIMSS & $\mathrm{H}_{2} \mathrm{O}$ intercept & No & Yes & No \\
\hline Meteosat-10 EUMETSAT & $\mathrm{CO}_{2}$ slicing & Yes & No & $\mathrm{Yes}^{\mathrm{a}}$ \\
\hline Meteosat-7 EUMETSAT & $\mathrm{H}_{2} \mathrm{O}$ intercept & Yes & Yes & No \\
\hline Global AVHRR EUMETSAT & $\mathrm{No}^{\mathrm{b}}$ & Yes & No & $Y_{e s}^{c}$ \\
\hline$M T S A T-2$ JMA & $\mathrm{H}_{2} \mathrm{O}$ intercept & No & Yes $^{\mathrm{d}}$ & $\mathrm{Yes}^{\mathrm{c}}$ \\
\hline
\end{tabular}

${ }^{\mathrm{a}}$ Heights from the external cloud product are weighted by individual pixel CCC and averaged.

${ }^{\mathrm{b}}$ Opportunistic use of collocated IASI $\mathrm{CO}_{2}$-slicing heights.

${ }^{\mathrm{c}}$ IR radiances are weighted by individual pixel CCC and averaged in EBBT.

${ }^{\mathrm{d}}$ Low-level IR AMVs above $850 \mathrm{hPa}$ are reassigned to $850 \mathrm{hPa}$ to eliminate a strong speed bias above this level. 
(García-Pereda 2016), but affects none of our conclusions. For example, selecting the AMV nearest to the MetOp AMV as the comparison wind increased the mean vector difference by $0.2-0.4 \mathrm{~m} \mathrm{~s}^{-1}$ but otherwise led to the same qualitative results.

To investigate height-assignment differences, we made calculations both with and without imposing the $\leq 25$-hPa vertical-separation constraint. Comparison statistics were derived separately for the globe (full-disk/ hemispheric average), tropics $\left(25^{\circ} \mathrm{S}-25^{\circ} \mathrm{N}\right)$, Northern Hemisphere $\left(25^{\circ}-90^{\circ} \mathrm{N}\right)$, and Southern Hemisphere $\left(25^{\circ}-90^{\circ} \mathrm{S}\right)$ as well as for low-level $(>700 \mathrm{hPa})$, midlevel $(400-700 \mathrm{hPa})$, and high-level $(<400 \mathrm{hPa})$ winds. Results were also stratified by MetOp height-assignment method (EBBT or IASI $\mathrm{CO}_{2}$ slicing). We only considered AMVs with QI $\geq 80$ - a typical threshold value for data assimilation (Forsythe and Saunders 2008). For compatibility with the 10.8- $\mu \mathrm{m}$ MetOp winds, only IR validation AMVs were used (with the exception of MISR, which provides daytime visible AMVs exclusively).

\section{Comparison results}

\section{a. Collocation frequency}

The total number of collocations between MetOp and comparison winds as a function of MetOp AMV pressure is given in Fig. 1. Results were dominated by the EBBT height-assignment method, which was employed for over $90 \%$ of MetOp winds. IASI heights were used in only $3 \%-10 \%$ of collocations, which were overwhelmingly at mid- to high levels above $700 \mathrm{hPa}$.

The collocation profiles showed the same relative vertical variation for all GEO comparison AMVs (Fig. 1a): a major peak at low levels between 800 and $900 \mathrm{hPa}$, a considerable decrease at midlevels with a minimum between 600 and $700 \mathrm{hPa}$, and a secondary maximum at high levels between 200 and $300 \mathrm{hPa}$. Lower midlevel collocations with JMA MTSAT-2 AMVs were particularly rare because of the forced reassignment of higher IR winds to $850 \mathrm{hPa}$, resulting in practically no JMA AMVs in the $600-850-\mathrm{hPa}$ layer (see also Fig. 12b, described in more detail below).

It has been found previously that high-quality GEO AMVs are scarce at midlevel (Forsythe and DoutriauxBoucher 2005; Lonitz and Horváth 2011). Both the $\mathrm{CO}_{2}$-slicing and $\mathrm{H}_{2} \mathrm{O}$-intercept methods lose sensitivity and are less reliable at midlevel, where the presence of multilayer clouds is also a common compounding factor (Borde and Dubuisson 2010). This layer represents a transition in height-assignment technique as the semitransparency methods dominating at higher levels change to the EBBT method favored at lower levels.
There might also be a nonlinear shift in EBBT heights from cloud top to cloud base. The larger retrieval uncertainty combined with mixed height-assignment methods tends to lower the AMV QI in this layer through spatial and temporal height-consistency tests. In sum, the shape of these collocation profiles is mostly driven by vertical variation in the frequency of highquality GEO AMVs, although a reduction in the number of midlevel AVHRR AMVs observed in the tropics is a contributing factor (Borde et al. 2016).

Collocation profiles for non-GEO comparison winds, MODIS and MISR AMVs and radiosonde observations, showed considerably different vertical variations (Fig. 1b). The vast majority of matches with high-quality MODIS AMVs were found at higher midlevels between 400 and $500 \mathrm{hPa}$, and there were few collocations above $300 \mathrm{hPa}$ and at low levels. Over polar areas, the tropopause is relatively low (typically located at 250-300 hPa), which explains the reduced number of high-level MODIS AMVs relative to GEO AMVs. The polar regions are also characterized by the frequent occurrence of optically thin low-level clouds, especially in the summer, and ubiquitous temperature inversions, both of which pose a significant challenge to the EBBT method. As a result, low-level MODIS AMVs generally have more uncertain height assignment and lower QI than their mid/high-level counterparts. Not surprising is that MODIS AMVs exhibit the largest differences with radiosonde winds at low levels (Key et al. 2003), where they are usually excluded from operational assimilation by forecast centers (Salonen et al. 2015).

In contrast, most collocations with high-QI MISR AMVs were located at low levels between 800 and $900 \mathrm{hPa}$, above which the number of matches steadily decreased with height. This was due to the fact that the MISR stereo matchers are by design more sensitive to low-level cloud patterns, where contrast in reflectivity is the highest. Note that MISR's preferable sampling of the lower levels can be an important addition to MODIS's strength of sampling the higher levels, because frequent and accurate wind observations below $700 \mathrm{hPa}$ were found to have a positive impact on NWP forecasts (Baker et al. 2014). Collocations with radiosonde winds were by far the fewest; they were the most evenly distributed, however, showing relatively little vertical variation in frequency.

The geographic distribution of collocations (not shown) revealed that matches with high-quality GEO AMVs were more frequent over ocean and the Southern Hemisphere than over land and the Northern Hemisphere. Collocations were most numerous in areas of extensive marine stratus/stratocumulus fields, especially in the southern oceans and the Atlantic Ocean. A similar 

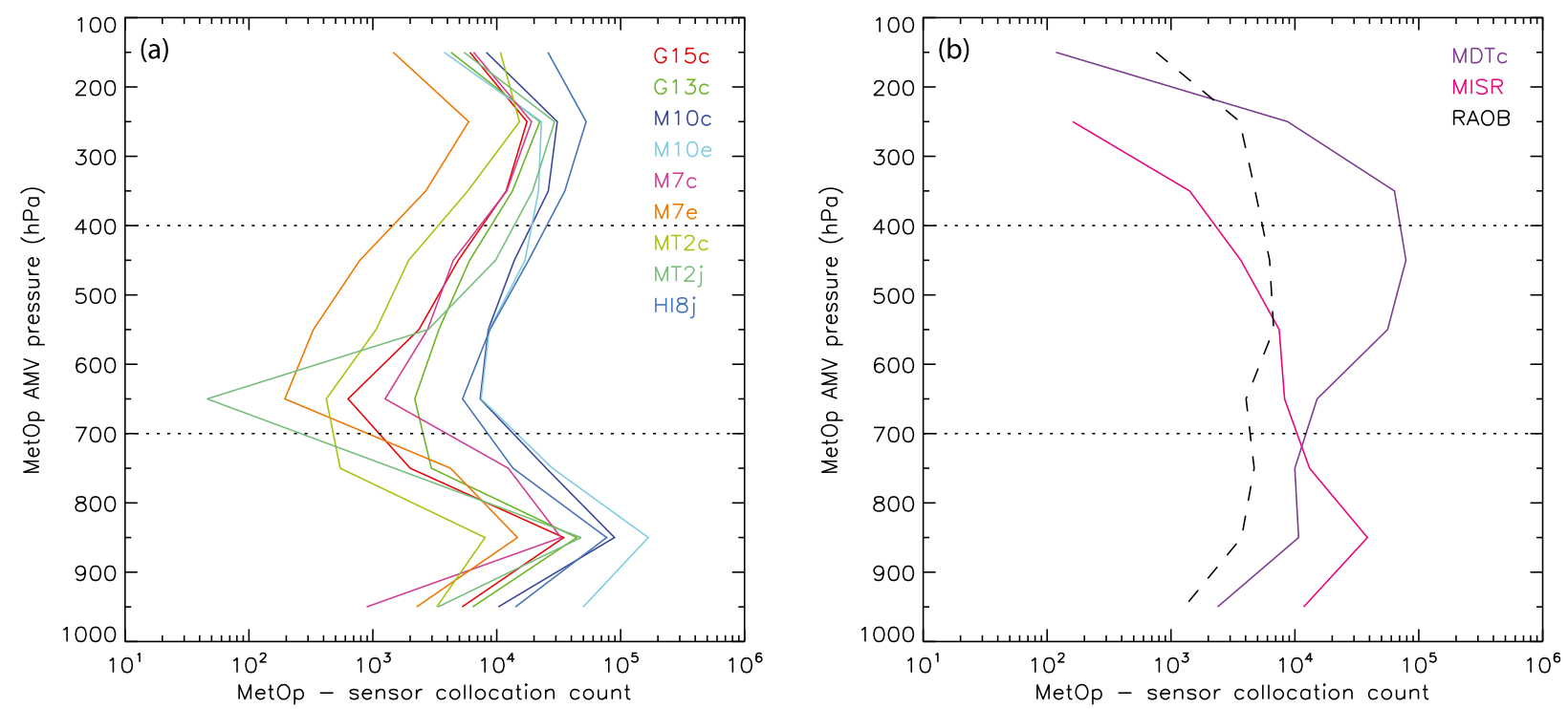

FIG. 1. Collocation frequency of MetOp AMVs with (a) GEO AMVs and (b) MODIS AMVs, MISR AMVs, and radiosonde winds (dashed line), as a function of MetOp AMV pressure. The CGMS spatial and temporal collocation thresholds were used. Dataset labels are given in Table 1.

land-ocean contrast was previously observed in the QI of Meteosat-9 AMVs (Lonitz and Horváth 2011). We also found more matches with MODIS AMVs in the Arctic than in the Antarctic, reflecting the contrast in summertime cloudiness between the polar regions. Of the satellite AMVs, MISR yielded the fewest matches with MetOp because of its narrow swath. MISR AMVs had near-global coverage, however, and their collocations with MetOp AMVs were spatially homogeneous, exhibiting much smaller regional variations than MetOp collocations with GEO and MODIS AMVs.

The absolute number of collocations depends on instrumental, algorithmic, and archival characteristics of the various datasets and, therefore, is difficult to compare directly. What can be said with confidence is that the newest sensors with finer spatial, temporal, and spectral characteristics (Meteosat-10 and Himawari-8) provided far more high-quality AMVs and thus collocations than their less capable predecessors (Meteosat-7 and MTSAT-2). The size of the cloud target could also have a noticeable effect on the number of AMVs. For example, there were more MetOp collocations with CIMSS AMVs than with the corresponding EUMETSAT AMVs, only slightly so for Meteosat-10 but significantly so for Meteosat-7, because the CIMSS algorithm tracks smaller cloud structures than does the EUMETSAT one (Table 1). Although a comparative analysis of the geographic and vertical sampling density of the different AMV datasets was beyond the scope of our paper, this could be a rewarding topic for future exploration.

\section{b. Mean statistics}

The MetOp wind speed bias, RMSD, and speed correlation relative to the comparison datasets are shown in Figs. 2, 3, and 4, respectively, separately for all, low-level, midlevel, and high-level AMVs as well as for the globe (full disk), tropics, and Northern/ Southern Hemispheres. These statistics were calculated using the standard vertical collocation threshold and are also listed in the online supplemental material (Tables S1-S3).

The column-mean MetOp AMV speed bias typically varied between -1 and $+2 \mathrm{~ms}^{-1}$ depending on region, with the tropics exhibiting the largest positive values-that is, MetOp winds were faster there than comparison winds (Fig. 2). The hemispherically averaged (global) bias fluctuated within a smaller range of $\pm 0.5 \mathrm{~m} \mathrm{~s}^{-1}$ because of partial cancellation of regional differences. Note that MetOp AMVs were practically unbiased when compared with radiosonde and model winds on a global basis.

Low-level AMVs had the smallest, and usually also positive, biases, which were typically below $0.5 \mathrm{~m} \mathrm{~s}^{-1}$ and varied little with latitude band. Midlevel winds showed larger biases between -0.5 and $+1.5 \mathrm{~m} \mathrm{~s}^{-1}$, again tending to be positive in most regions. High-level winds had the largest biases between -2.5 and $+4.5 \mathrm{~m} \mathrm{~s}^{-1}$, with positive biases in the tropics and negative biases outside the tropics. In general, both the magnitude and the zonal variability of the speed bias increased with height against most validation datasets, although the increase in normalized speed bias was less sharp, rising from \pm 0.03 to 

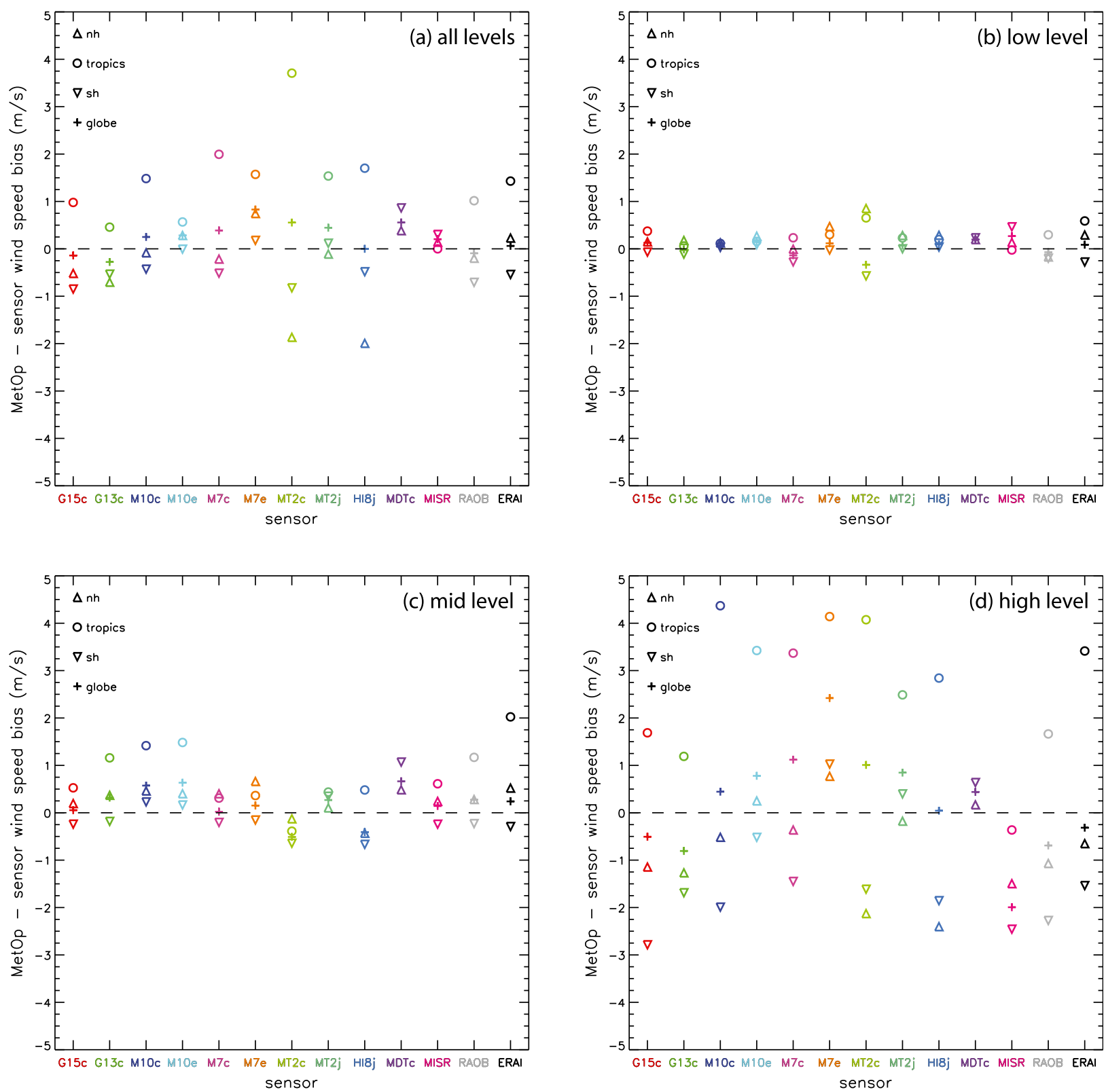

FIG. 2. MetOp-vs-sensor wind speed bias averaged for (a) all levels, (b) low level ( $>700 \mathrm{hPa}),(\mathrm{c})$ midlevel (400-700 hPa), and (d) high level $(<400 \mathrm{hPa})$, separately for the tropics $\left(25^{\circ} \mathrm{S}-25^{\circ} \mathrm{N}\right)$, Northern Hemisphere (label nh; $\left.25^{\circ}-90^{\circ} \mathrm{N}\right)$, Southern Hemisphere (label sh; $25^{\circ}-90^{\circ} \mathrm{S}$ ), and the globe (for GEO and MODIS polar AMVs, "globe" refers to full-disk/hemispheric mean). The CGMS spatial and temporal collocation thresholds were used.

\pm 0.04 to \pm 0.05 for the three height layers, because the mean wind also strengthened with altitude from 10-12 to $16-20$ to $21-28 \mathrm{~m} \mathrm{~s}^{-1}$, respectively. The notable exception was the MODIS polar AMV product, the speed bias against which only had a weak vertical variation, and the comparison was even slightly more favorable at high level than midlevel.

Wind speed RMSD showed a similar tendency with height, increasing from $1.5-3.5$ to $3.0-5.0$ to
$4.0-7.0 \mathrm{~m} \mathrm{~s}^{-1}$ from low to mid- to high level, respectively (Fig. 3). The normalized speed RMSD generally increased with height also, from $0.15-0.18$ to $0.19-0.23$ to $0.20-0.26$. The column-mean RMSD typically varied between 2.5 and $5.5 \mathrm{~m} \mathrm{~s}^{-1}$ and was the smallest against MISR because of the strong dominance of low-level retrievals among collocations with stereo AMVs. Also note that for low-level winds the RMSD was the largest against radiosonde observations, 

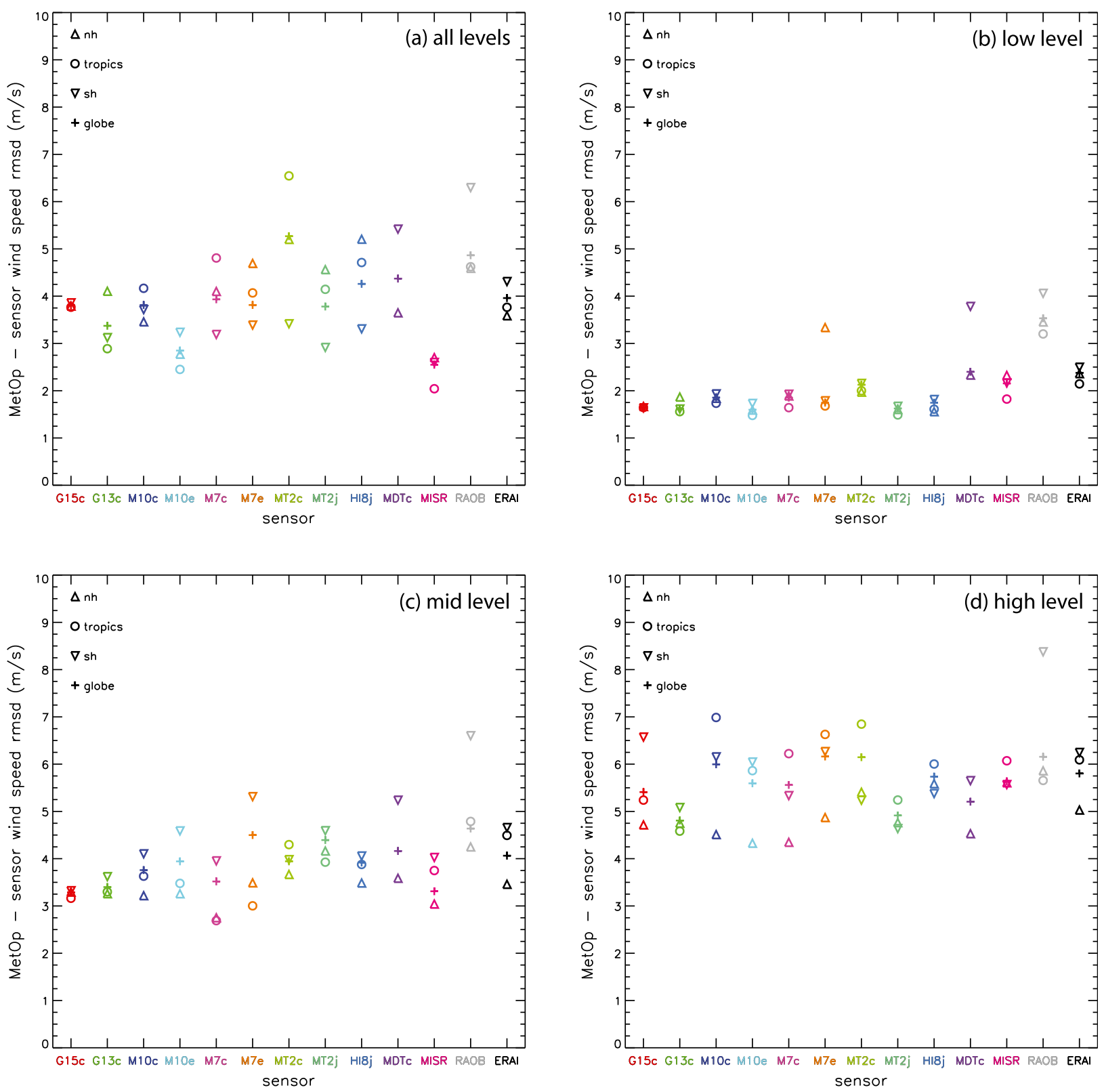

FIG. 3. As in Fig. 2, but for wind speed RMSD.

$3.5 \mathrm{~m} \mathrm{~s}^{-1}$, whereas it was usually $\sim 2 \mathrm{~m} \mathrm{~s}^{-1}$ or less against satellite AMVs.

Wind speed correlation considering all levels was typically between 0.88 and 0.98 and tended to be the highest in the Southern Hemisphere (Fig. 4). In the tropics, speed correlation could be as low as 0.6-0.7, especially for high-level winds. At low and midlevels, the speed correlation with radiosonde observations was considerably smaller than that with satellite winds. The reduced speed correlation and larger RMSD noted above might be indicative of temporal/spatial-scale differences between radiosonde winds and MetOp
AMVs because the former are instantaneous point measurements whereas the latter represent the mean motion of a cloud field of hundreds of square kilometers over $\sim 50 \mathrm{~min}$. The validation against raobs is also relatively sensitive to collocation thresholds, especially the maximum allowed horizontal separation (García-Pereda 2016). The poorer statistics might additionally be related to analyzing only summertime data from Northern Hemisphere land areas, where most of the raob stations are located. The comparison might be better for boreal winter when midlatitude flow is more organized. 

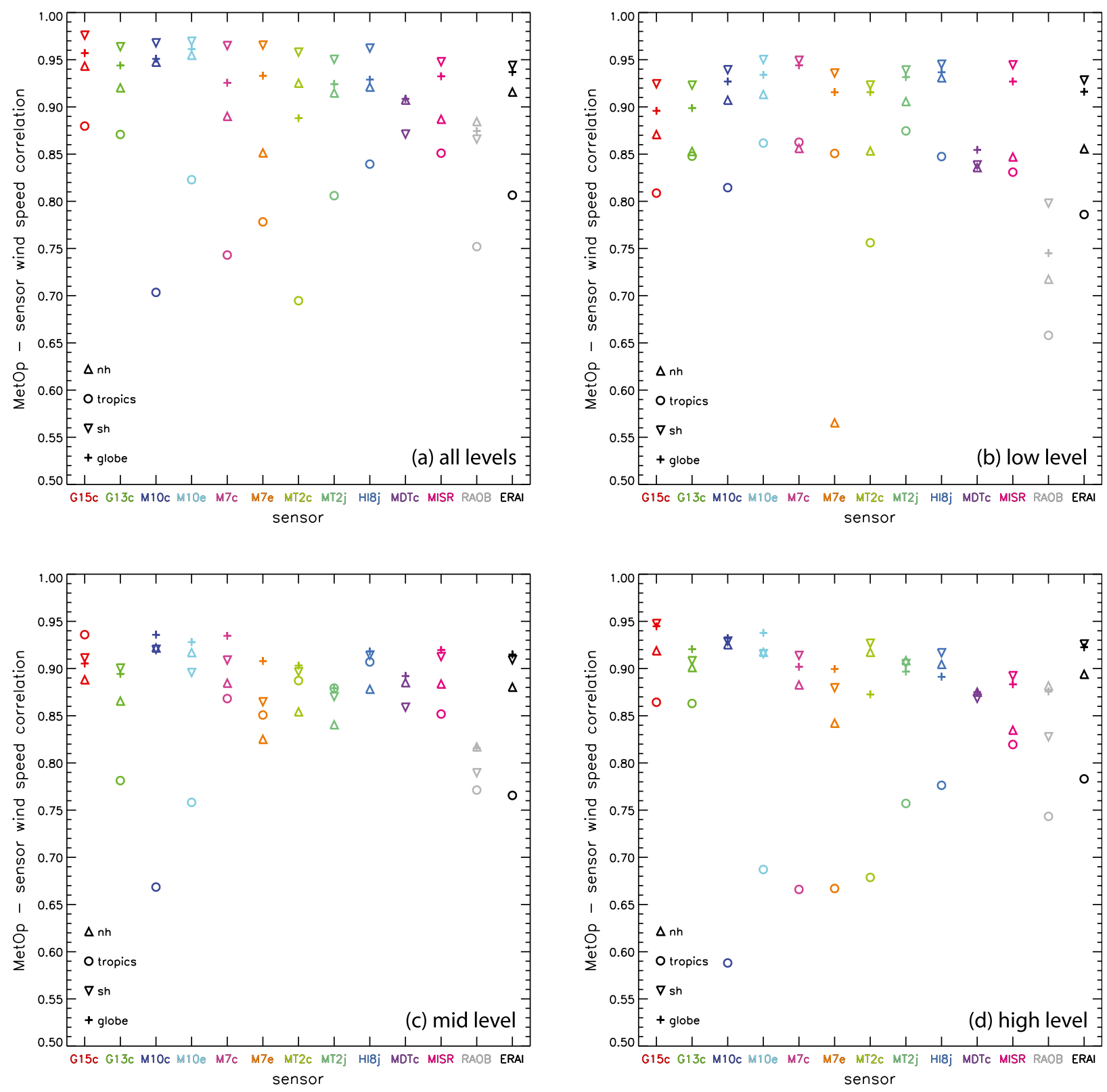

FIG. 4. As in Fig. 2, but for wind speed correlation.

Overall, the most striking feature of MetOp AMVs in comparison with the validation datasets was a bias toward faster speeds accompanied by a significantly reduced speed correlation and increased RMSD at mid- and high levels in the tropics. As will be shown below, the positive speed bias is present even at the highest altitudes, and, therefore, a negative bias in MetOp heights due to semitransparency effects is unlikely to provide a full explanation.

\section{c. Vertical variations}

The geographically averaged (full-disk or global mean) vertical profiles of speed bias, RMSD, and speed correlation as a function of MetOp AMV height are plotted in Fig. 5, separately for GEO and non-GEO comparison winds. The bias at low and midlevels showed good consistency among the validation datasets, varying between \pm 0.5 and $\pm 1.0 \mathrm{~m} \mathrm{~s}^{-1}$, respectively, with a positive bias being somewhat more frequent than a bias toward slower speeds (Figs. 5a,b). At high levels, the bias values had a larger spread between -2.0 and $+5.5 \mathrm{~m} \mathrm{~s}^{-1}$. The highest-altitude bin $(100-200 \mathrm{hPa})$ showed strong positive MetOp speed biases relative to GEO and model winds. At low and midlevels, speed biases relative to non-GEO winds were comparable in 

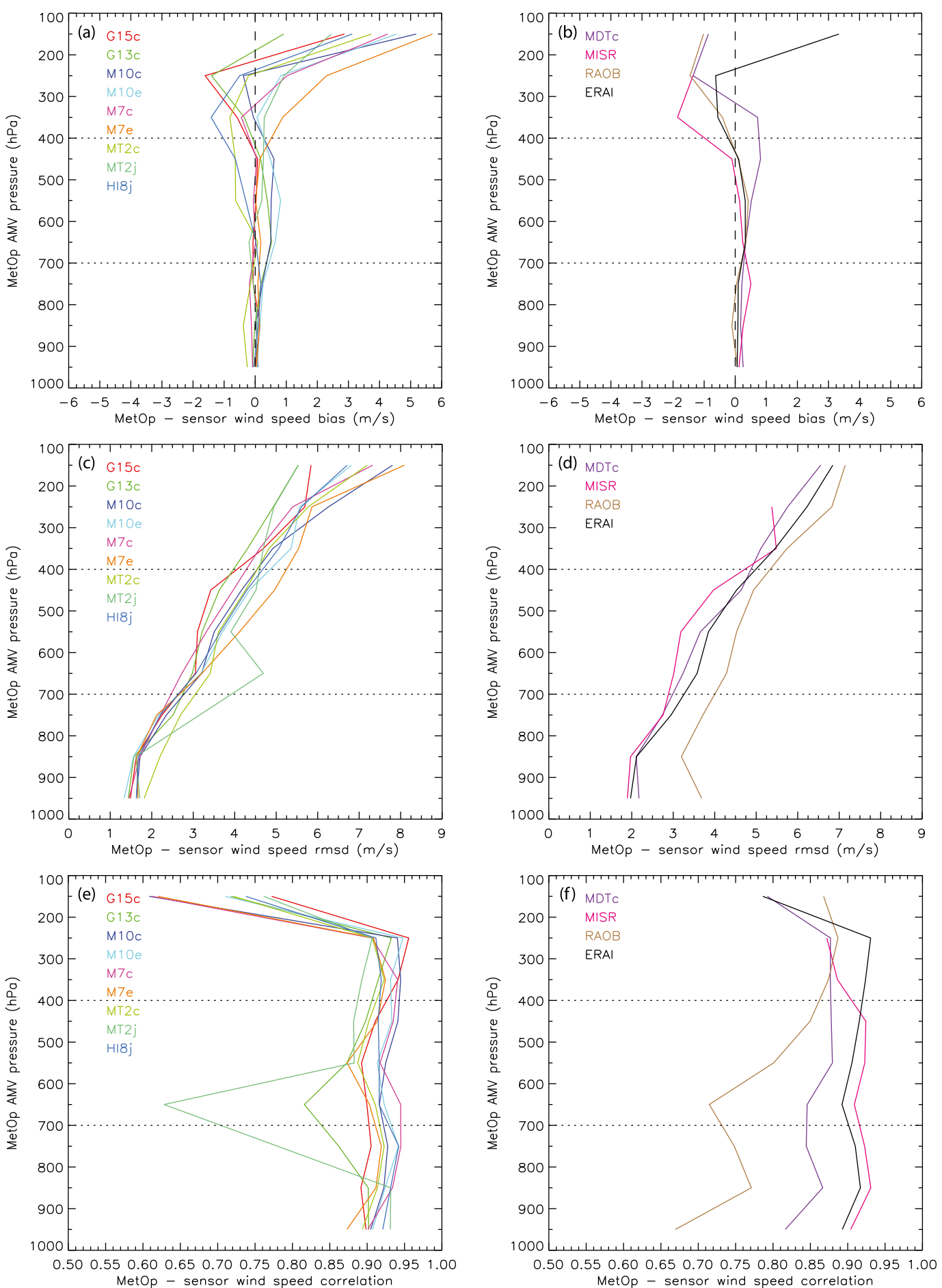

FIG. 5. MetOp-vs-sensor wind speed (a),(b) bias, (c),(d) RMSD, and (e),(f) correlation as a function of MetOp AMV pressure, separately for (left) GEO AMVs and (right) non-GEO winds. The CGMS spatial and temporal collocation thresholds were used. 
magnitude to those against GEO winds and similarly were more positive than negative. At the highest level, however, MetOp had negative speed biases against MODIS, MISR, and radiosonde winds, which were smaller in magnitude than the strong positive biases against GEO and model winds. This was likely related to the reduced sampling of the tropics and the different spatiotemporal characteristics of these non-GEO datasets.

There were no significant differences between MetOp speed biases relative to CIMSS and EUMETSAT retrievals apart from the high-level positive bias against Meteosat-7 winds being $\sim 1.5 \mathrm{~m} \mathrm{~s}^{-1}$ larger for EUMETSAT AMVs than for CIMSS AMVs. In a similar way, MetOp had comparable biases relative to CIMSS and JMA MTSAT-2 winds, with JMA AMVs showing only marginally better agreement.

Speed RMSD increased close to linearly with height from $1-2 \mathrm{~m} \mathrm{~s}^{-1}$ at the lowest level to $5-8 \mathrm{~m} \mathrm{~s}^{-1}$ at the highest level with relatively little dependence on validation dataset (Figs. 5c,d). Two points can be noted here, though. First, the RMSD in the $600-700-h P a$ layer was considerably larger against JMA MTSAT-2 AMVs than against any other dataset. This result was due to the forced reassignment of most midlevel JMA MTSAT-2 AMVs to the 850-hPa level. Second, RMSD values generally were the largest in comparison with radiosonde winds, especially at low and midlevels, perhaps indicating scaling (representativeness) issues as noted before.

Speed correlation was typically between 0.85 and 0.95 with the exception of the highest-altitude bin, which had much lower values between 0.60 and 0.80 (Figs. 5e,f). There was also a less pronounced secondary minimum at midlevels. Similar to RMSD, the comparisons with JMA MTSAT-2 and radiosonde winds were outliers here also. MetOp AMVs showed by far the smallest speed correlation (0.63) in the 600-700-hPa layer with JMA MTSAT-2 AMVs for the reasons discussed previously. The speed correlation with radiosonde winds, on the other hand, was overall the poorest among the validation datasets, especially at low and midlevels. We found no major differences between results against CIMSS and EUMETSAT retrievals other than speed correlations with Meteosat-7 winds being slightly smaller when using EUMETSAT AMVs. Note that MISR visible AMVs surprisingly had one of the best overall speed correlations with MetOp IR AMVs, perhaps because of the similar target sizes and LEO view geometries.

\section{d. Geographic variations}

Geographic variations of MetOp wind speed bias, RMSD, and speed correlation are mapped in Figs. 6, 7, and 8, separately for low, mid-, and high levels as well as the column mean but averaged for both height-assignment methods. For illustration purposes, we used GOES-15, GOES-13, and MODIS Terra AMVs from CIMSS, Meteosat-10 and Meteosat-7 AMVs from EUMETSAT, and Himawari-8 AMVs from JMA as comparison data, but the results were qualitatively the same when JMA MTSAT-2 AMVs and CIMSS Meteosat AMVs were considered instead.

As shown, high-quality low-level MetOp winds were overwhelmingly located over ocean while high-quality mid- and high-level winds were more evenly distributed between land and ocean. The same dependence on quality control-that is, QI $>80$ low-level AMVs being mostly over ocean and high-quality AMVs over land being mostly at mid- and high levels-was also observed in EUMETSAT Meteosat- 9 winds by Horváth (2013) and probably results from orographic effects, which reduce the number of high-contrast, long-lived passive cloud tracers. Using a lower threshold of QI $>60$ would have yielded many more low-level MetOp AMVs over land.

Low- and midlevel MetOp AMVs had a positive bias in most regions except for portions of the Southern Ocean, with typical magnitudes of $<1$ and $<3 \mathrm{~m} \mathrm{~s}^{-1}$, respectively. The speed bias was largest and showed the strongest zonal variation for high-level MetOp winds: a marked bias toward faster winds in the tropics up to and beyond $3 \mathrm{~m} \mathrm{~s}^{-1}$, a mostly negative bias at midlatitudes-although with positive biases over Europe and western Russia-and again a bias toward faster winds in the polar regions. As a result, the column-mean speed bias was mostly dominated by the strong tropical positive bias. Column-mean negative biases were found over the midlatitude parts of the MTSAT-2/Himawari-8 and GOES-15/GOES-13 coverage areas. The columnmean MetOp speed bias against stereo AMVs (not shown) exhibited little geographic variation and was typically a weak positive bias because of MISR's preferential sampling of the lower levels.

The corresponding speed RMSD increased with height, typically being $<3,<5$, and $<8 \mathrm{~m} \mathrm{~s}^{-1}$ for low-, mid-, and high-level MetOp AMVs, respectively. The low-level RMSD had little regional variation, but the mid- and high-level RMSD were somewhat larger along the intertropical convergence zone (ITCZ) and at midlatitudes than in other regions. The resulting columnmean RMSD was the largest $\left(7-8 \mathrm{~m} \mathrm{~s}^{-1}\right)$ along the ITCZ and especially over the Indo-Pacific warm pool, was lower $\left(4-5 \mathrm{~m} \mathrm{~s}^{-1}\right)$ at midlatitudes, and was the smallest $\left(1-2 \mathrm{~m} \mathrm{~s}^{-1}\right)$ in subtropical oceans dominated by lowlevel marine stratus/stratocumulus fields.

The most prominent feature of the speed correlation maps was a band of considerably lower values in 

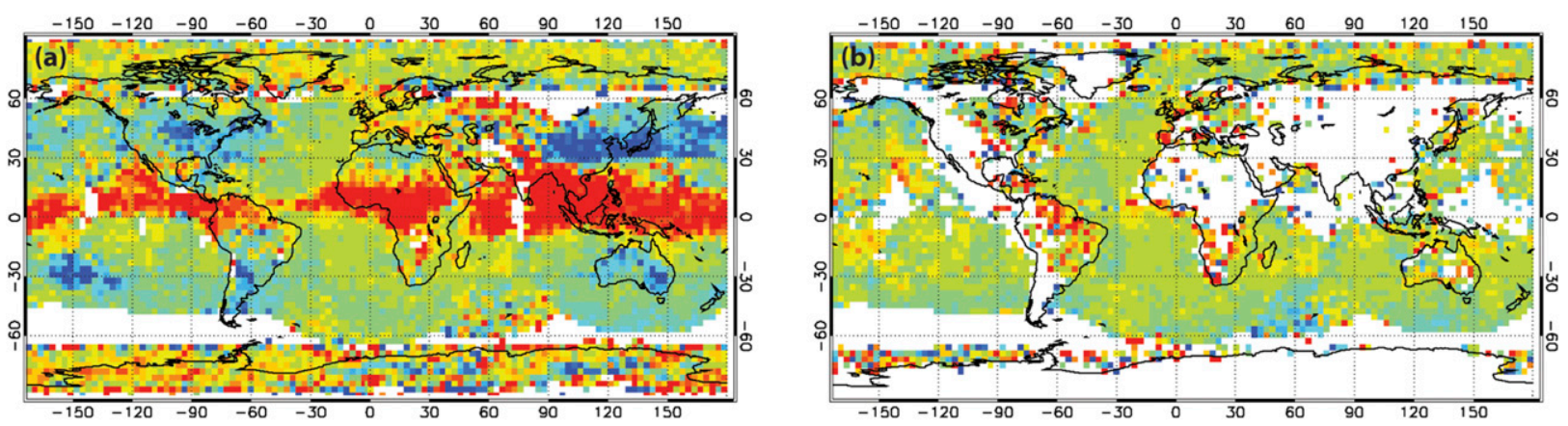

wind speed bios $(\mathrm{m} / \mathrm{s})$

\begin{tabular}{lllllllll}
\hline & -2 & -1 & 0 & 1 & 2 & 3
\end{tabular}
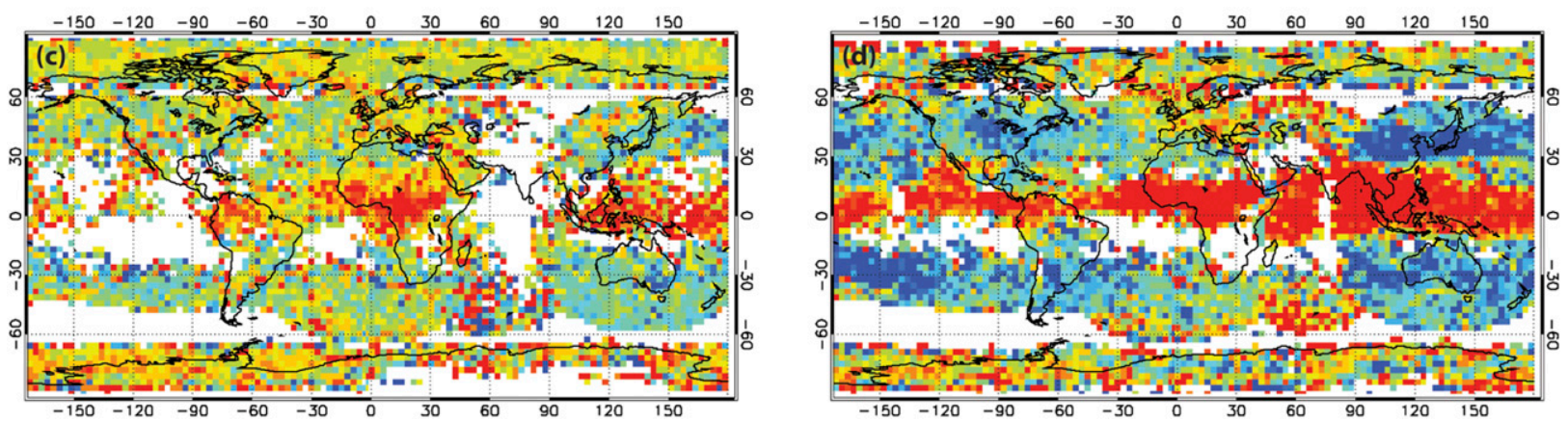

FIG. 6. Geographic distribution of MetOp wind speed bias against (from west to east) GOES-15 CIMSS, GOES-13 CIMSS, Meteosat-10 EUMETSAT, Meteosat-7 EUMETSAT, Himawari-8 JMA geostationary AMVs, and MODIS Terra CIMSS polar AMVs averaged for (a) all levels, (b) low level, (c) midlevel, and (d) high level. The CGMS spatial and temporal collocation thresholds were used.

the tropics at all levels. Speed correlation was generally the highest at midlatitudes, especially in the Southern Hemisphere. A land-ocean contrast was also apparent, with speed correlation tending to be smaller over the former than over the latter.

\section{e. Best-fit wind statistics}

Scatter density plots of MetOp versus best-fit comparison wind pressure are shown for the various validation datasets in Figs. 9-14. Here, we selected the comparison AMV that minimizes the vector difference with the MetOp AMV irrespective of the pressure difference between the retrievals; that is, the $\leq 25-\mathrm{hPa}$ CGMS vertical collocation constraint was relaxed. These plots include all MetOp AMVs; pressure scatterplots for the small subset of primarily mid- to high-level AMVs assigned to IASI heights are given in the online supplemental material (Figs. S1 and S2). Also shown are the corresponding box-and-whisker plots of the distributions of MetOp minus best-fit pressure difference as a function of MetOp pressure, separately for the EBBT and IASI height-assignment methods. Here, positive or negative pressure differences indicate a best-fit comparison AMV at a higher altitude or a lower altitude, respectively, than the MetOp AMV.
The scatterplots indicate that CIMSS AMVs were assigned to discrete pressure levels, which was the consequence of the recursive filter scheme readjusting the initial radiometric-based AMV heights to minimize deviation from model information. The EUMETSAT, JMA, and MISR height assignments, in contrast, produced continuous pressure distributions. It is also evident that height correlation was generally much worse for low-level AMVs than for mid-high-level AMVs. The height- and speed-comparison statistics between MetOp and best-fit validation winds are summarized in Tables 3 and 4, separately for low and mid-high levels and EBBT and IASI heightassignment methods.

The EBBT pressure difference profile showed a reverse "S" shape for all but the visible-channel MISR comparison AMVs: best-fit winds tended to be at a higher altitude than the lowest-level (900-1000 hPa) and midlevel MetOp winds, at a lower altitude than upper lower-level (700-900 hPa) MetOp winds, and at a similar or slightly lower altitude than the highest-level (100-200 hPa) MetOp winds. The largest pressure differences were observed at the boundary between low and midlevels $(600-700 \mathrm{hPa})$, with the distribution being widest for JMA MTSAT-2 AMVs 

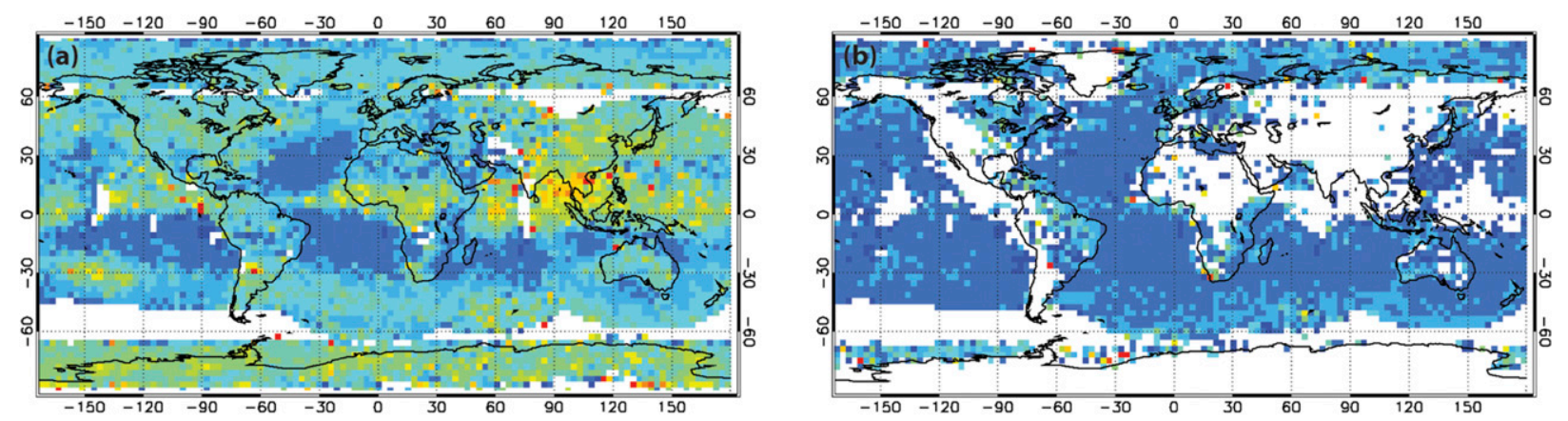

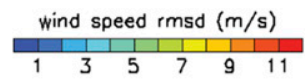
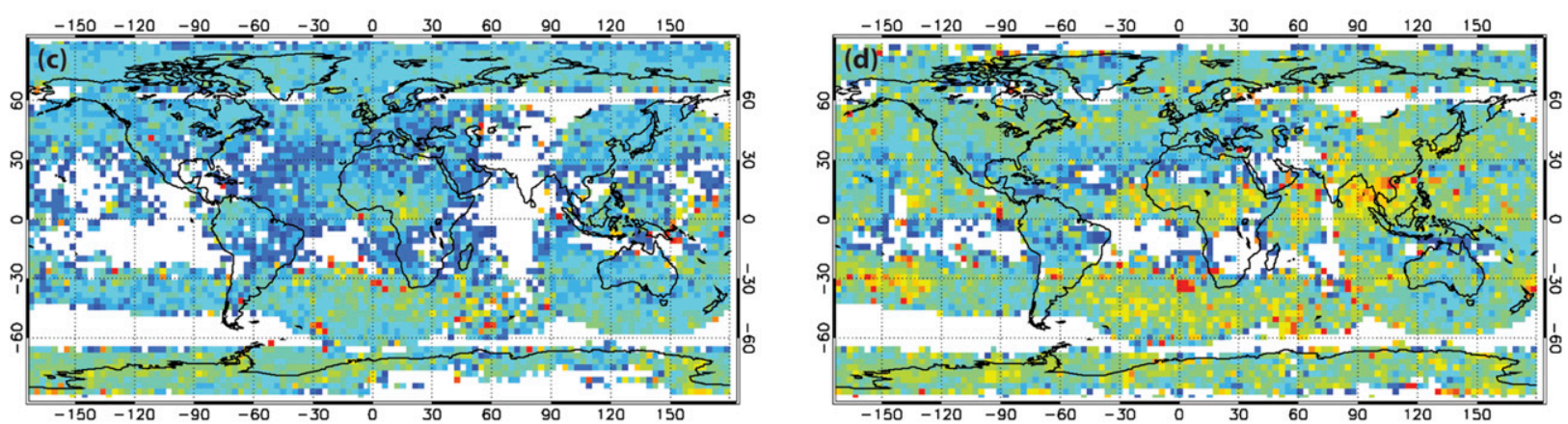

FIG. 7. As in Fig. 6, but for wind speed RMSD.

because of the artificial shift of lower midlevel winds to $850 \mathrm{hPa}$ (Fig. 12d). Note that Warrick (2015) found a similarly shaped EBBT best-fit pressure difference profile between dual-mode MetOp AMVs and Met Office global-model winds.

The pressure discrepancies at low levels were driven by differences in the triggering and type (cloud-base or inversion method) of height adjustment. The exact criteria for applying height adjustment vary among wind-extraction schemes-even between the GEO and LEO versions of the EUMETSAT algorithm-and can lead to both positive and negative height differences. For example, the mainly positive best-fit pressure differences at the lowest level were likely due to cases in which inversion adjustment was applied to MetOp AMVs but comparison AMVs had no height adjustment. Conversely, the vertical stripes in Fig. 10b correspond to collocations in which inversion adjustment was applied to EUMETSAT Meteosat-10 AMVs but not to MetOp AMVs-similar stripes in pressure scatterplots of these two datasets were also observed by Borde et al. (2016).

The result of the differing height-adjustment strategies was a very poor correlation between MetOp and GEO AMV pressures at low levels, as listed in Table 3 but also visually obvious in the scatterplots. The lowlevel speed comparison, in contrast, was very good, with bias, RMSD, and speed correlation usually better than $0.15 \mathrm{~m} \mathrm{~s}^{-1}, 2.00 \mathrm{~m} \mathrm{~s}^{-1}$, and 0.90 , respectively, as shown in Table 4 . While pressure correlations were typically between 0.7 and 0.8 for mid-high-level winds, they were below 0.27 and could even be negative for low-level winds. It is not surprising that the pressure correlation was much improved when essentially the same heightassignment scheme was used for the compared retrievals. Switching from the CIMSS to the EUMETSAT scheme increased low-level pressure correlation from 0.11 to 0.72 for Meteosat-10 and from 0.24 to 0.50 for Meteosat-7 AMVs, accompanied by a reduction in RMSD as well. The improvement in low-level height comparison with EUMETSAT GEO AMVs was also clear in the box-and-whisker plots of best-fit pressure differences (Figs. 10 and 11).

The low-level pressure correlation with MODIS Terra and MISR AMVs, 0.49 and 0.58, respectively, was also considerably better than that with CIMSS and JMA GEO AMVs (Fig. 14). In general, the height comparison with MODIS was among the best. The pressure difference distribution was only significantly off zero and positive in the lowest MetOp altitude bin, which might have been due to frequent inversion adjustment in polar regions by the MetOp algorithm combined with the lack of the inversion method in the MODIS scheme (Olander 2001). 

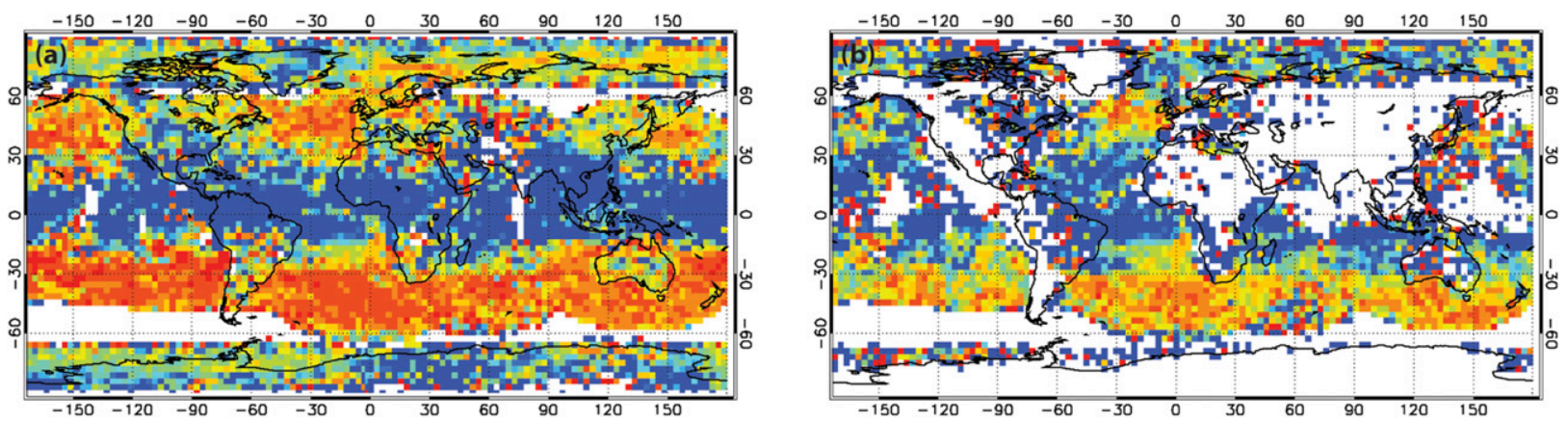

wind speed correlotion (\%)

$\begin{array}{llllllll}78 & 82 & 86 & 90 & 94 & 98\end{array}$
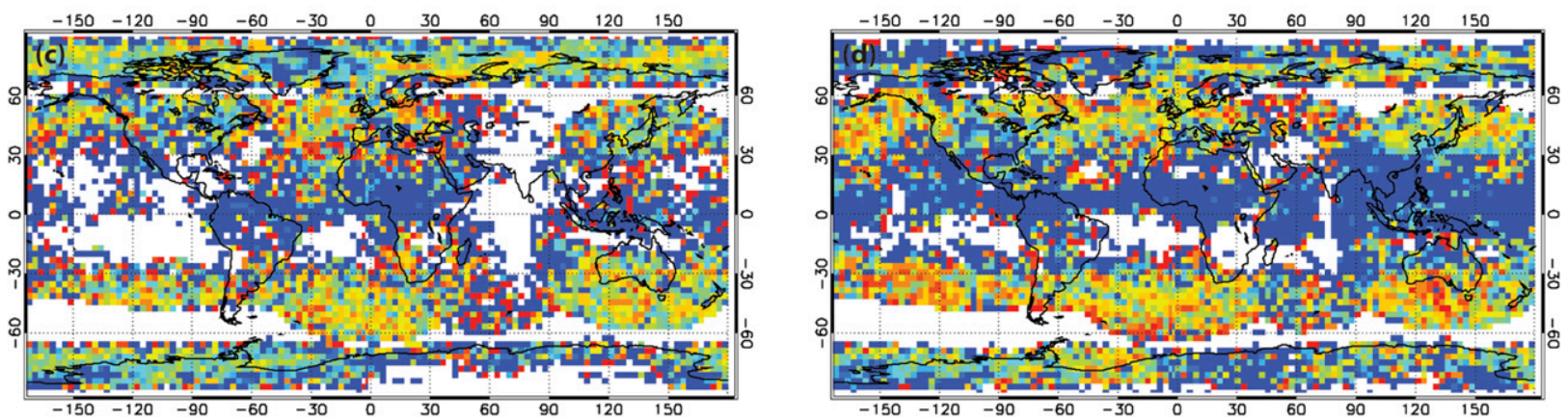

FIG. 8. As in Fig. 6, but for wind speed correlation.

The height agreement with MISR stereo AMVs was even better at low levels between 800 and $1000 \mathrm{hPa}$, comparable to the smallest differences found relative to EUMETSAT Meteosat-10 AMVs. At mid- and high levels, however, the pressure difference distribution systematically shifted to increasingly negative values as MetOp height increased. Image-contrast differences between the visible channel and the IR channel can lead to tracking mismatches in multilayer scenes, whereby $0.67-\mu \mathrm{m}$ stereo AMVs track low-level clouds while IR AMVs track upper-level clouds (Lonitz and Horváth 2011). MISR AMVs are consequently dominated by low-level retrievals (Fig. 1b), resulting in a preference for a best-fit wind match below the MetOp AMV height.

The MetOp EBBT heights between 300 and $700 \mathrm{hPa}$ also tended to be lower than best-fit wind heights, even when compared with EUMETSAT GEO AMVs. This was likely due to the lack of semitransparency correction in thinner clouds, where IR radiation from below-cloud layers can introduce biases toward warmer brightness temperatures and lower EBBT heights. Note that this midlevel pressure bias was much smaller against MODIS Terra AMVs retrieved in cold polar regions (Fig. 14c). The box-and-whisker plots and Table 3 clearly indicate that using IASI $\mathrm{CO}_{2}$-slicing heights increased the MetOp AMV altitude and thus considerably reduced the height bias and RMSD and increased the height correlation relative to most datasets. The two exceptions were the comparisons with MODIS Terra and MISR. For the former, the EBBT best-fit pressure differences were already centered close to zero; for the latter, they tended to be negative because of MISR's preferential sampling of low levels. Therefore, higher IASI heights made the pressure bias larger and negative in both cases.

In summary, IASI heights represented an improvement over EBBT heights for MetOp mid-high-level AMVs, but they were only available in $\sim 5 \%$ of the retrievals. The speed difference statistics of MetOp AMVs assigned to IASI heights were comparable to those assigned to EBBT heights, with similar speed RMSD and correlation and only slightly larger values of speed bias (Table 4).

\section{Summary}

Two months of MetOp AMVs from EUMETSAT's new dual-mode global AVHRR wind product, version 2.5 , were evaluated against independent wind data as part of ongoing validation efforts. The validation dataset included CIMSS, JMA, and EUMETSAT geostationary AMVs, MODIS Terra and MISR polar-orbiter AMVs, IGRA radiosonde winds, and ERA-Interim model winds. Comparison statistics were calculated separately for the globe (full-disk/hemispheric average), Northern Hemisphere, tropics, and Southern Hemisphere as well 

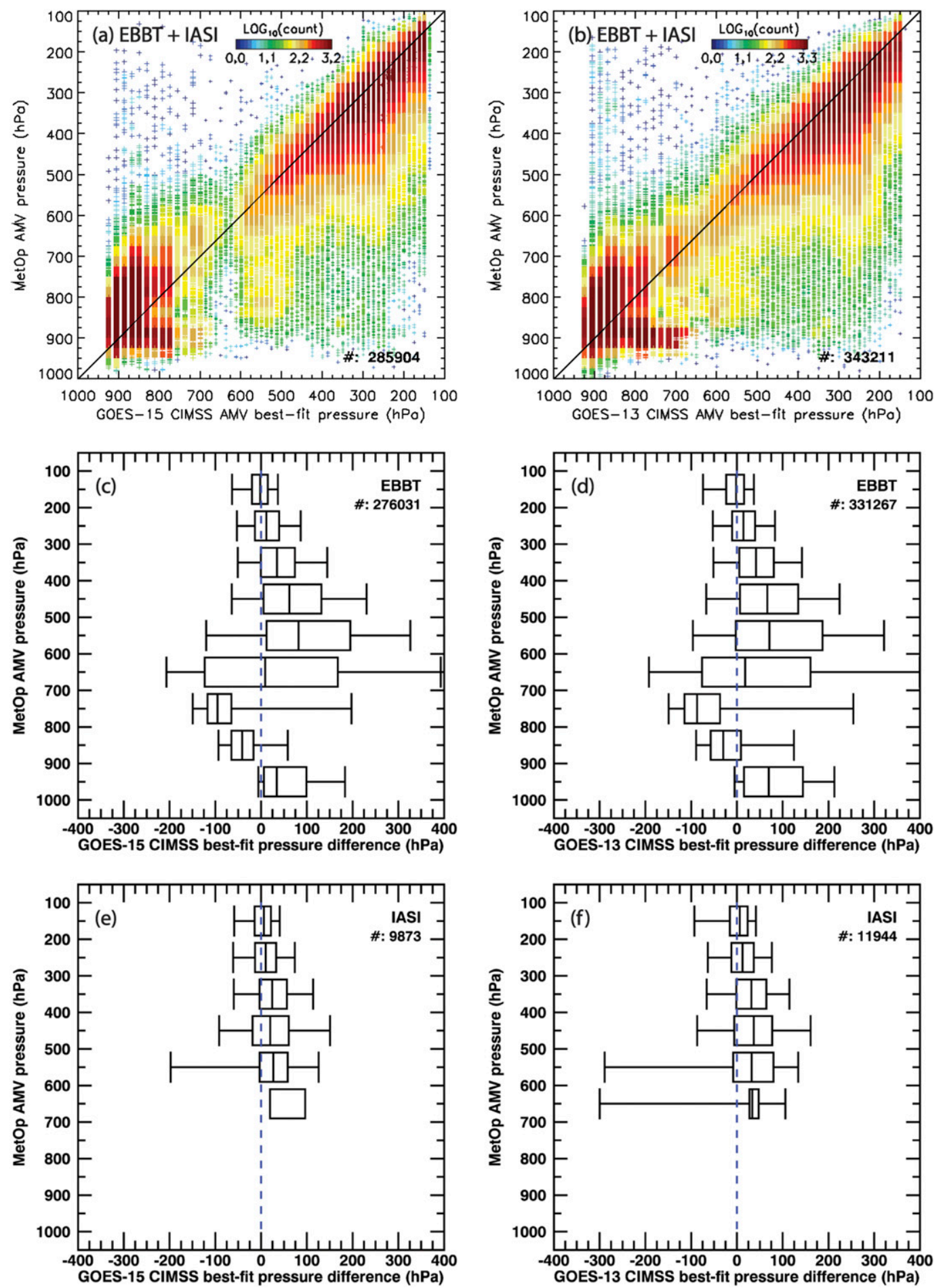

FIG. 9. MetOp AMV pressure vs best-fit validation AMV pressure for (left) GOES-15 CIMSS and (right) GOES-13 CIMSS winds. The (a),(b) pressure scatterplots include all MetOp AMVs; colors from blue to dark red correspond to increasing logarithmic number frequency. The box-and-whisker plots of best-fit pressure differences (5th percentile, 25th percentile, median, 75th percentile, and 95th percentile) are shown as a function of MetOp AMV height, separately for the (c),(d) EBBT and (e),(f) IASI methods. The number of collocated wind pairs is also indicated. 

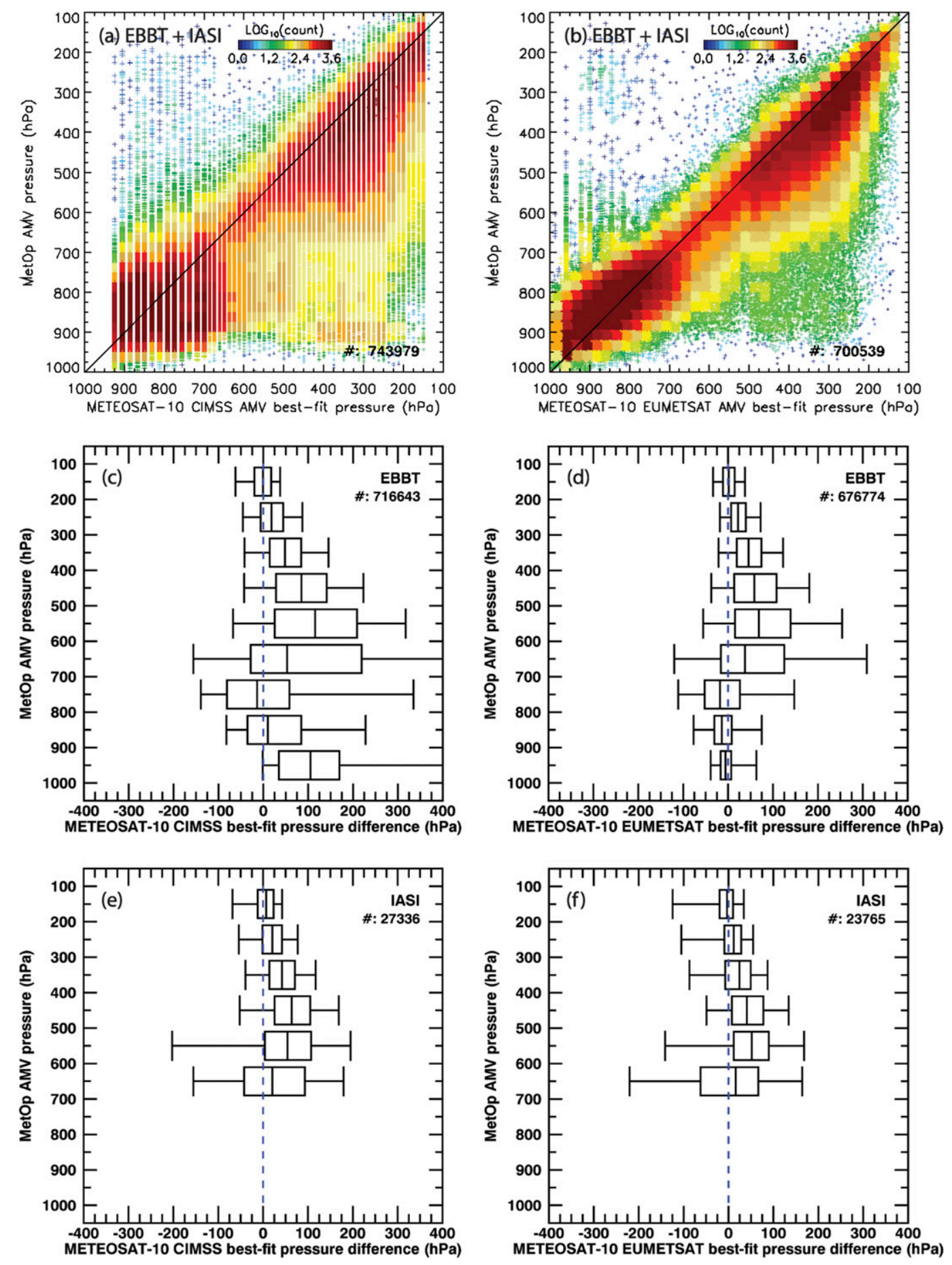

FIG. 10. As in Fig. 9, but for MetOp vs (a),(c),(e) Meteosat-10 CIMSS and (b),(d),(f) Meteosat-10 EUMETSAT AMVs.

as for AMVs assigned to EBBT or IASI $\mathrm{CO}_{2}$-slicing heights.

The MetOp AMV speed bias and RMSD relative to validation winds were generally comparable to differences in observation wind minus model background wind reported for other AMV products by the Numerical Weather Prediction Satellite Application Facility (http://nwpsaf.eu). High-level MetOp AMVs, however, showed a bias toward slower winds outside the tropics and a strong bias toward faster winds 

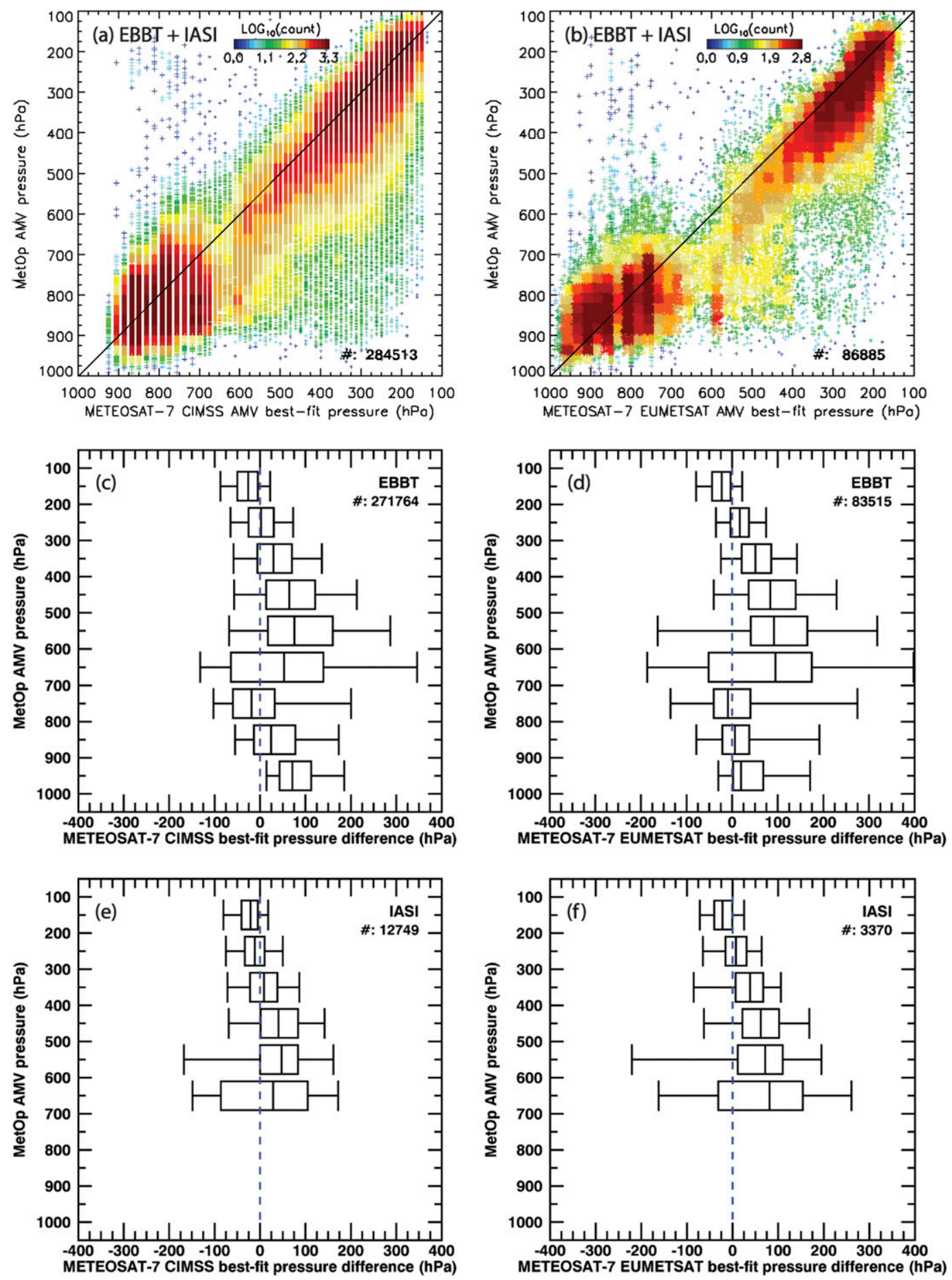

FIG. 11. As in Fig. 9, but for MetOp vs (a),(c),(e) Meteosat-7 CIMSS and (b),(d),(f) Meteosat-7 EUMETSAT AMVs.

along the ITCZ, which dominated the column-mean results. The high-level tropical positive speed bias was also accompanied by increased RMSD, and speed correlation was significantly reduced in the tropics at all levels.
A best-fit wind analysis indicated generally very poor correlation between low-level MetOp and comparison AMV heights, despite good agreement in speed. This was most likely due to differences in the type and triggering of height adjustments. Low-level AMVs are 

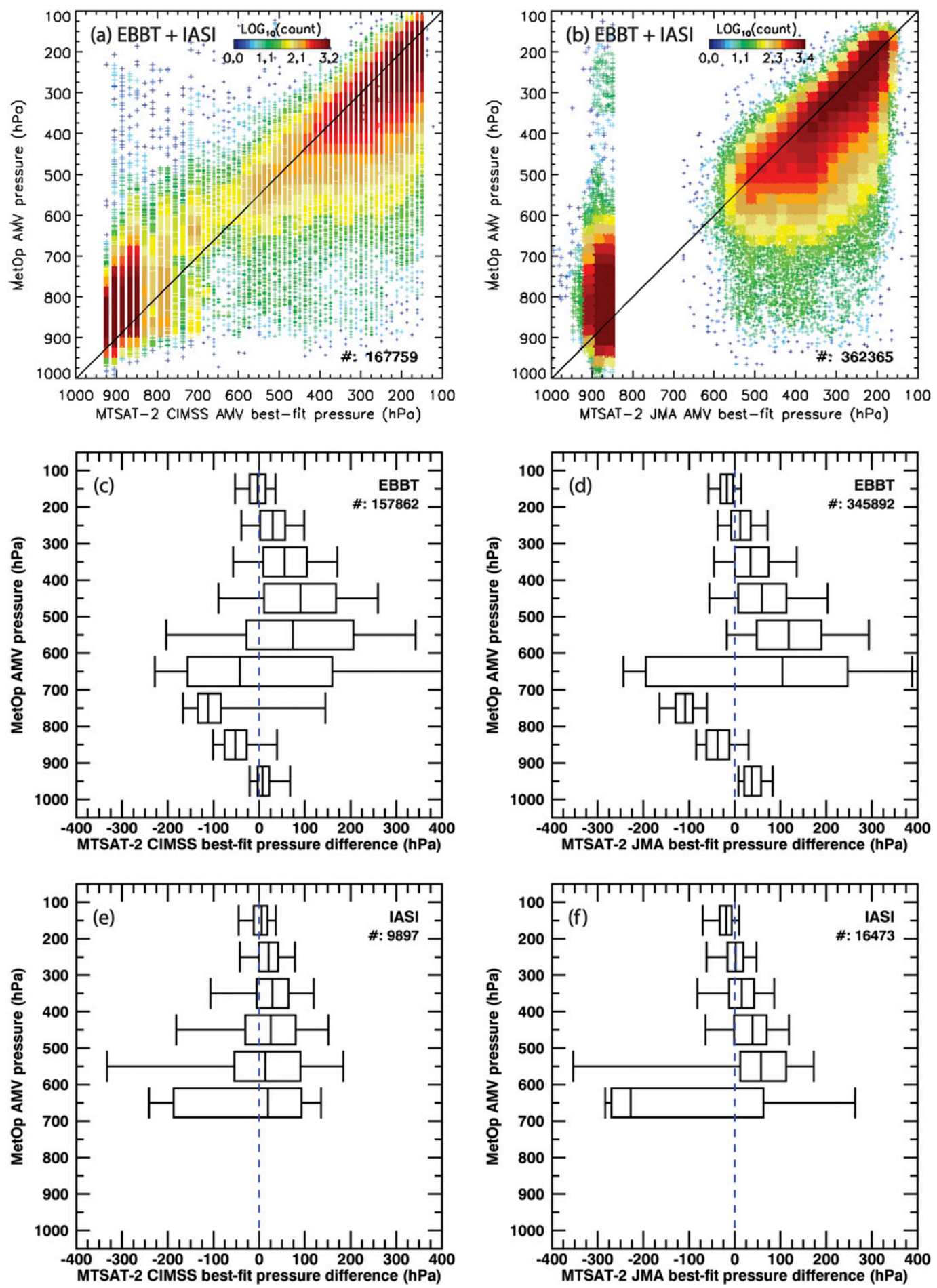

FIG. 12. As in Fig. 9, but for MetOp vs (a),(c),(e) MTSAT-2 CIMSS and (b),(d),(f) MTSAT-2 JMA AMVs.

occasionally assigned either to an estimated cloud-base height or to the bottom of a temperature inversion rather than the EBBT cloud-top height, but the exact criteria for these adjustments vary among AMV producers. Not surprising is that the best height agreement was observed with low-level EUMETSAT GEO AMVs, which use a similar, although not identical, heightassignment scheme.

The widest distributions in best-fit pressure difference were found at the boundary of low and midlevels 

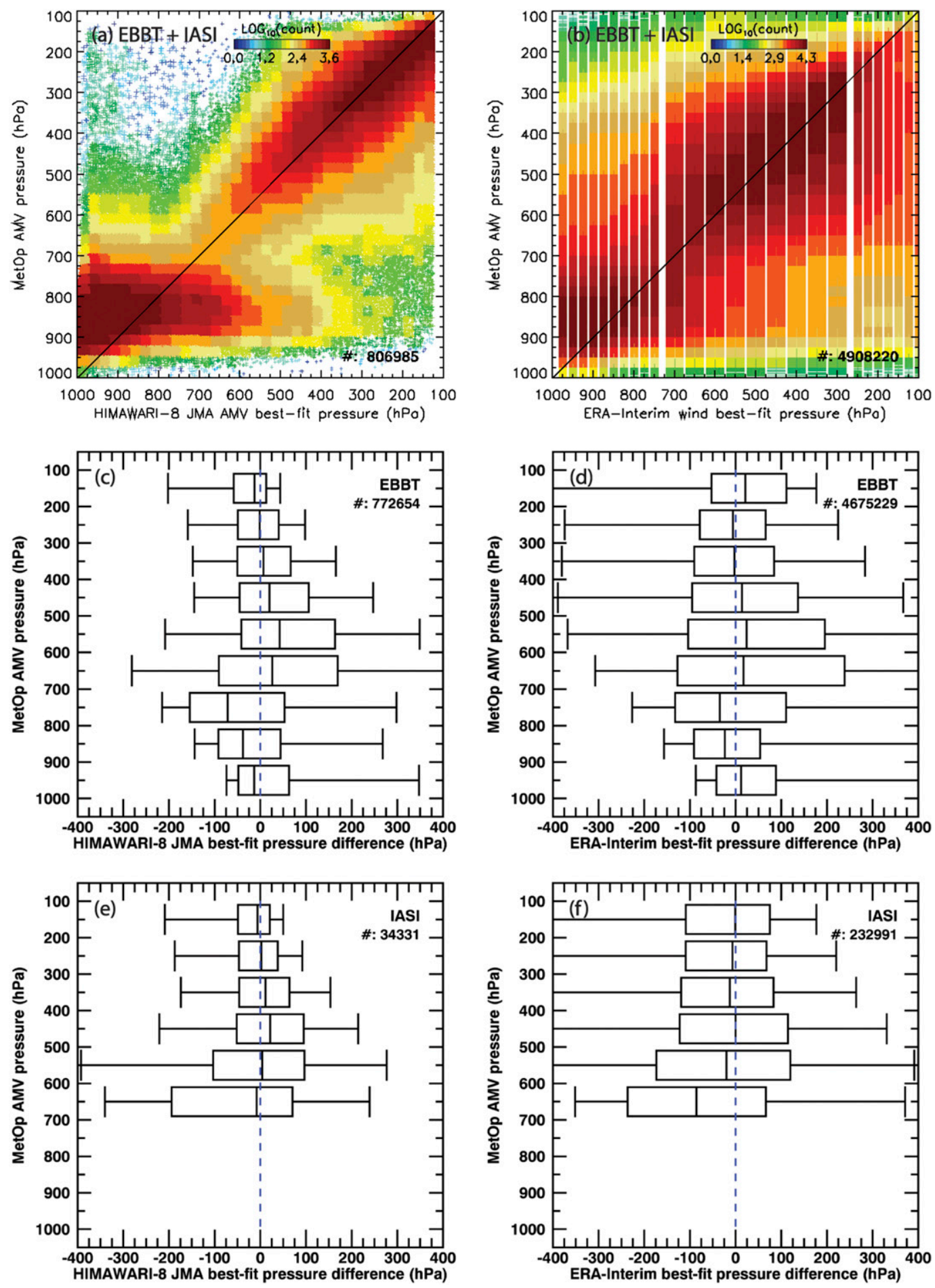

FIG. 13. As in Fig. 9, but for MetOp vs (a),(c),(e) Himawari-8 JMA AMVs and (b),(d),(f) ERA-Interim winds.

$(600-700 \mathrm{hPa})$, where height assignment in most AMV retrieval schemes makes a transition from the EBBT to the $\mathrm{CO}_{2}$-slicing or $\mathrm{H}_{2} \mathrm{O}$-intercept methods. Nevertheless, height correlation was significantly better between mid-high-level AMVs than between low-level ones, although MetOp EBBT heights in the 300-700-hPa layer were biased toward lower values relative to validation AMVs, including even EUMETSAT GEO AMVs. This was due to the lack of water vapor and $\mathrm{CO}_{2}$ channels on AVHRR, prohibiting semitransparency 

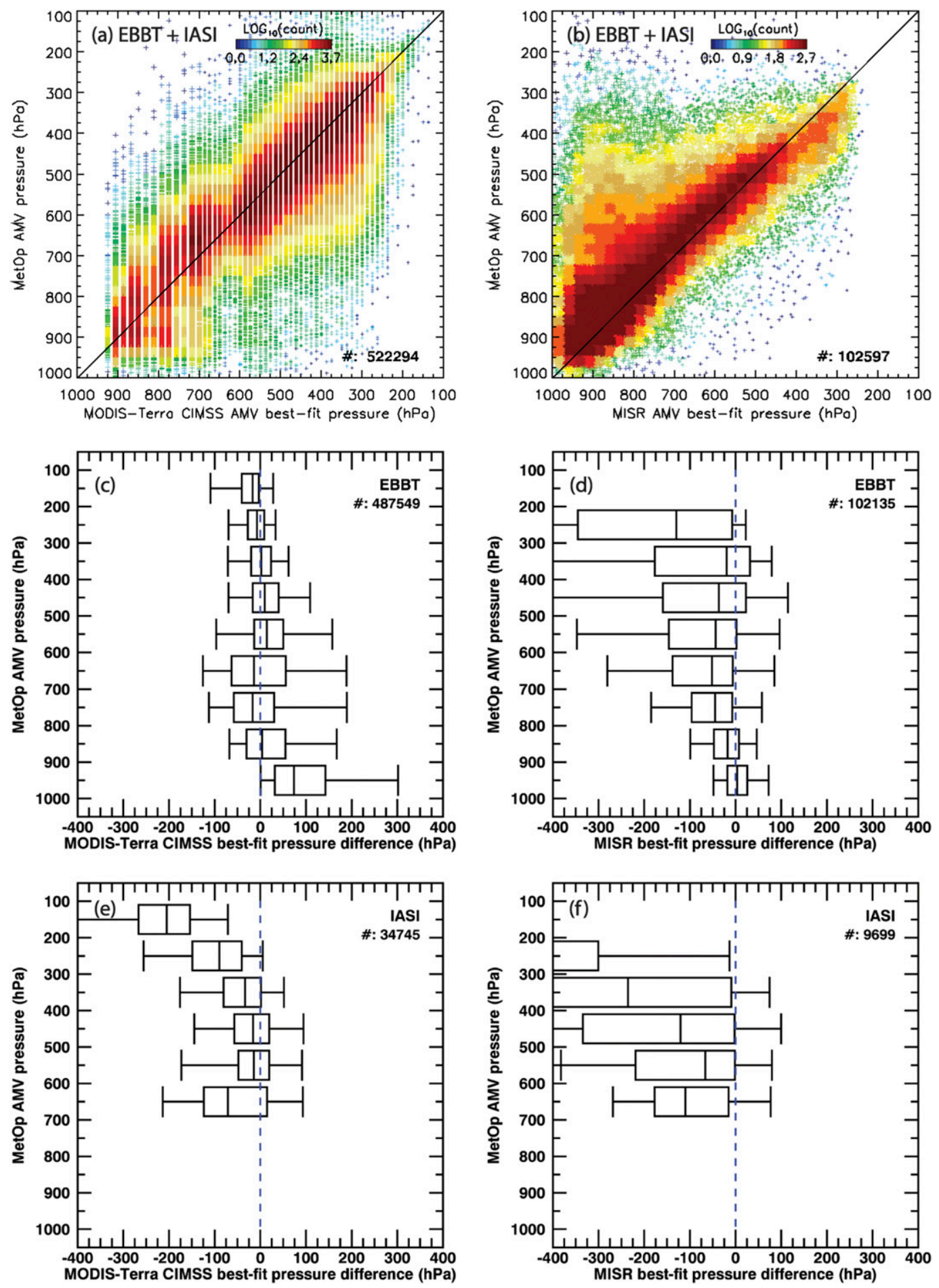

FIG. 14. As in Fig. 9, but for MetOp vs (a),(c),(e) MODIS Terra CIMSS and (b),(d),(f) MISR AMVs.

corrections in thin clouds where radiation from lower and warmer atmospheric layers bias the EBBT height toward lower values. Use of collocated IASI $\mathrm{CO}_{2}$-slicing heights, however, considerably reduced this negative bias and further increased height correlation, without negatively affecting the good mid-high-level speed comparison statistics. IASI heights were unfortunately only available for $\sim 5 \%$ of MetOp AMVs.

Validation statistics against raob winds were generally comparable to those against satellite and model winds. 
TABLE 3. Height comparison between MetOp and best-fit validation winds separately for low (both winds below $700 \mathrm{hPa}$ ) and mid-high (both winds above $700 \mathrm{hPa}$ ) levels and EBBT and IASI height assignment.

\begin{tabular}{|c|c|c|c|c|c|c|c|c|c|}
\hline \multirow[b]{2}{*}{ Dataset } & \multicolumn{3}{|c|}{ Height bias (hPa) } & \multicolumn{3}{|c|}{ Height RMSD (hPa) } & \multicolumn{3}{|c|}{ Height correlation } \\
\hline & $\begin{array}{c}\text { EBBT } \\
\text { low }\end{array}$ & $\begin{array}{c}\text { EBBT } \\
\text { mid-high }\end{array}$ & $\begin{array}{c}\text { IASI } \\
\text { mid-high }\end{array}$ & $\begin{array}{c}\text { EBBT } \\
\text { low }\end{array}$ & $\begin{array}{c}\text { EBBT } \\
\text { mid-high }\end{array}$ & $\begin{array}{c}\text { IASI } \\
\text { mid-high }\end{array}$ & $\begin{array}{c}\text { EBBT } \\
\text { low }\end{array}$ & $\begin{array}{c}\text { EBBT } \\
\text { mid-high }\end{array}$ & $\begin{array}{c}\text { IASI } \\
\text { mid-high }\end{array}$ \\
\hline G15c & -43 & +49 & +16 & 69 & 101 & 52 & 0.15 & 0.74 & 0.82 \\
\hline G13c & -21 & +52 & +21 & 72 & 103 & 56 & -0.05 & 0.74 & 0.79 \\
\hline M10c & +8 & +73 & +37 & 77 & 121 & 69 & 0.11 & 0.71 & 0.81 \\
\hline M10e & -13 & +58 & +20 & 44 & 93 & 58 & 0.72 & 0.83 & 0.83 \\
\hline $\mathrm{M} 7 \mathrm{c}$ & +14 & +39 & +2 & 64 & 92 & 54 & 0.24 & 0.80 & 0.87 \\
\hline M7e & 0 & +56 & +20 & 55 & 98 & 64 & 0.50 & 0.78 & 0.79 \\
\hline MT2c & -59 & +49 & +19 & 78 & 99 & 55 & 0.27 & 0.74 & 0.84 \\
\hline MT2j & -49 & +51 & +7 & 69 & 94 & 45 & -0.08 & 0.72 & 0.87 \\
\hline HI8j & -48 & +18 & 0 & 95 & 112 & 89 & 0.19 & 0.66 & 0.65 \\
\hline MDTc & +3 & +16 & -40 & 67 & 64 & 89 & 0.49 & 0.82 & 0.64 \\
\hline MISR & -28 & -16 & -49 & 63 & 84 & 120 & 0.58 & 0.69 & 0.46 \\
\hline ERAI & -46 & +72 & +19 & 99 & 201 & 162 & 0.28 & 0.34 & 0.42 \\
\hline
\end{tabular}

At low and midlevels, however, speed RMSD was the largest and speed correlation was the smallest relative to radiosonde observations, perhaps indicating representativeness differences between instantaneous point measurements and cloud-scale averages over $\sim 50 \mathrm{~min}$.

Overall, the most troubling issue found by our study is the poor performance of dual-mode MetOp winds in the tropics, which was also noticed in more limited comparisons by Borde et al. (2016) and Warrick (2016). The MetOp AMV positive speed bias was consistently present relative to all satellite AMVs as well as model winds. From a comparison with Met Office global-model winds, Warrick (2016) suggested that the bias toward faster winds is partly due to IR limb cooling at large off-nadir view angles, where the radiative effect of a longer optical path through the absorbing atmosphere combined with the geometric effect of obscured clear-sky gaps between clouds leads to anomalously low brightness temperatures and thus EBBT heights that are positively biased. In our study, however, we found no view-angle dependence of the comparison statistics. Furthermore, an AMV altitude that is biased toward a higher height only leads to a bias toward faster speed in the case of negative vertical wind shear. In the more typical case of wind speed increasing with altitude, a positive AMV height bias would entail a negative speed bias.

The MetOp tropical fast bias is unlikely to be explained by height-assignment errors alone, although limb-cooling and semitransparency effects should be further investigated in combination with model estimates of vertical wind shear. Parallax correction, which is important for overlapping LEO imagery, also needs to be reevaluated because the apparent shift in target location at off-nadir view angles is greatest precisely in the tropics at high levels. Target-size and image-frequency differences between MetOp and validation winds could

TABLE 4. As in Table 3, but for speed comparison.

\begin{tabular}{|c|c|c|c|c|c|c|c|c|c|}
\hline \multirow[b]{2}{*}{ Dataset } & \multicolumn{3}{|c|}{ Speed bias $\left(\mathrm{m} \mathrm{s}^{-1}\right)$} & \multicolumn{3}{|c|}{ Speed RMSD $\left(\mathrm{m} \mathrm{s}^{-1}\right)$} & \multicolumn{3}{|c|}{ Speed correlation } \\
\hline & $\begin{array}{c}\text { EBBT } \\
\text { low }\end{array}$ & $\begin{array}{c}\text { EBBT } \\
\text { mid-high }\end{array}$ & $\begin{array}{c}\text { IASI } \\
\text { mid-high }\end{array}$ & $\begin{array}{c}\text { EBBT } \\
\text { low }\end{array}$ & $\begin{array}{c}\text { EBBT } \\
\text { mid-high }\end{array}$ & $\begin{array}{c}\text { IASI } \\
\text { mid-high }\end{array}$ & $\begin{array}{c}\text { EBBT } \\
\text { low }\end{array}$ & $\begin{array}{l}\text { EBBT } \\
\text { mid-high }\end{array}$ & $\begin{array}{c}\text { IASI } \\
\text { mid-high }\end{array}$ \\
\hline G15c & +0.13 & -1.21 & -1.35 & 1.60 & 6.06 & 5.82 & 0.91 & 0.91 & 0.91 \\
\hline G13c & +0.02 & -1.45 & -1.64 & 1.55 & 5.78 & 5.73 & 0.92 & 0.88 & 0.89 \\
\hline M10c & +0.06 & -1.11 & -1.74 & 1.79 & 6.64 & 6.98 & 0.93 & 0.90 & 0.91 \\
\hline M10e & +0.15 & -0.73 & -0.91 & 1.66 & 6.06 & 6.14 & 0.94 & 0.92 & 0.92 \\
\hline M7c & -0.07 & +0.11 & +0.27 & 1.85 & 5.81 & 5.78 & 0.94 & 0.89 & 0.90 \\
\hline M7e & +0.11 & +0.75 & +1.27 & 1.86 & 6.28 & 6.48 & 0.92 & 0.89 & 0.89 \\
\hline MT2c & -0.22 & -0.20 & -0.16 & 2.00 & 6.28 & 6.03 & 0.94 & 0.85 & 0.88 \\
\hline MT2j & +0.04 & +0.15 & +0.35 & 1.66 & 5.16 & 5.02 & 0.95 & 0.87 & 0.89 \\
\hline $\mathrm{HI} 8 \mathrm{j}$ & +0.07 & -0.54 & -0.60 & 1.68 & 5.97 & 5.88 & 0.94 & 0.87 & 0.89 \\
\hline MDTc & +0.13 & +0.20 & +0.80 & 2.46 & 4.63 & 5.16 & 0.85 & 0.89 & 0.88 \\
\hline MISR & +0.27 & +0.09 & +0.11 & 2.13 & 4.32 & 5.24 & 0.93 & 0.90 & 0.87 \\
\hline ERAI & +0.14 & +0.47 & +0.44 & 1.22 & 2.22 & 2.27 & 0.98 & 0.98 & 0.98 \\
\hline
\end{tabular}


be another source of speed discrepancy. For example, García-Pereda and Borde (2014) found generally faster AMVs for smaller target sizes. These and other potential causes linked to the specifics of tropical cloud dynamics (diurnal cycle of convection, gravity waves, etc.) warrant a detailed investigation.

We note that the future of the dual-mode global AVHRR wind product is somewhat uncertain, because $M e t O p-A$ is approaching the end of its guaranteed lifetime. Continued generation of global AVHRR winds is envisaged by pairing MetOp-B with the upcoming MetOp-C to be launched in 2018, but EUMETSAT currently is only contracted to provide single-mode polar AMVs. With or without such a pairing, the experience gained with this novel wind retrieval technique might spark interest in proposed missions that aim to produce a homogeneous global AMV dataset from LEO satellite constellations (e.g., Stoffelen et al. 2014).

Acknowledgments. This work was carried out while the first author was employed by the Leibniz Institute for Tropospheric Research, Leipzig, Germany, under EUMETSAT Tenders 207600 and 210693. The authors are indebted to Kazuki Shimoji of the Japan Meteorological Agency, the University of Wisconsin-Madison Cooperative Institute for Meteorological Satellite Studies, and the MISR team at the Jet Propulsion Laboratory for kindly providing their respective AMV datasets. The suggestions of three anonymous reviewers greatly improved the paper.

\section{REFERENCES}

Baker, N. L., P. M. Pauley, R. H. Langland, K. Mueller, and D. Wu, 2014: An assessment of the impact of the assimilation of NASA Terra MISR atmospheric motion vectors on the NRL Global Atmospheric Prediction System. Second Symp. on the Joint Center for Satellite Data Assimilation, Atlanta, GA, Amer. Meteor. Soc., J3.1. [Available online at https://ams. confex.com/ams/94Annual/webprogram/Paper231106.html.]

Bessho, K., and Coauthors, 2016: An introduction to Himawari-8/9Japan's new-generation geostationary meteorological satellites. J. Meteor. Soc. Japan, 94, 151-183, doi:10.2151/jmsj.2016-009.

Borde, R., and P. Dubuisson, 2010: Sensitivity of atmospheric motion vectors height assignment methods to semitransparent cloud properties using simulated Meteosat- 8 radiances. J. Appl. Meteor. Climatol., 49, 1205-1218, doi:10.1175/2010JAMC2352.1.

—, M. Doutriaux-Boucher, G. Dew, and M. Carranza, 2014: A direct link between feature tracking and height assignment of operational EUMETSAT atmospheric motion vectors. J. Atmos. Oceanic Technol., 31, 33-46, doi:10.1175/JTECH-D-13-00126.1.

, O. Hautecoeur, and M. Carranza, 2016: EUMETSAT global AVHRR wind product. J. Atmos. Oceanic Technol., 33, 429438, doi:10.1175/JTECH-D-15-0155.1.

Durre, I., R. S. Vose, and D. B. Wuertz, 2006: Overview of the Integrated Global Radiosonde Archive. J. Climate, 19, 53-68, doi:10.1175/JCLI3594.1.
EUMETSAT, 2015: AVHRR global winds product: Validation report. EUMETSAT Tech. Rep. EUM/TSS/REP/14/751801, $36 \mathrm{pp}$. [Available online at http://www.eumetsat.int/website/ $\mathrm{wcm} /$ idc/idcplg? IdcService $=$ GET_FILE $\&$ dDocName $=$ PDF $_{-}$ AVHRR_GLOBAL_WINDS_PVR\&RevisionSelectionMethod= LatestReleased\&Rendition $=$ Web.]

- 2016: AVHRR L2 wind product ATBD. EUMETSAT Tech. Rep. EUM/RSP/SPE/14/781004, 24 pp. [Available online at http://www.eumetsat.int/website/wcm/idc/idcplg? IdcService $=$ GET_FILE\&dDocName $=$ PDF_AVHRR_WIND_PROD_ ATBD\&RevisionSelectionMethod $=$ LatestReleased\&Rendition $=$ Web.]

Forsythe, M., and M. Doutriaux-Boucher, 2005: Second analysis of the data displayed on the NWP SAF AMV monitoring website. NWP SAF Tech. Doc. NWPSAF-MO-TR-020, 46 pp. [Available online at http://nwpsaf.eu/monitoring/amv/ nwpsaf_mo_tr_020.pdf.]

, and R. Saunders, 2008: Third analysis of the data displayed on the NWP SAF CMV monitoring website. NWP SAF Tech. Doc. NWPSAF-MO-TR-022, 50 pp. [Available online at http://nwpsaf.eu/monitoring/amv/nwpsaf_mo_tr_022.pdf.]

García-Pereda, J., 2016: Scientific and validation report for the wind product processors of the NWC/GEO. NWC SAF Tech. Doc. NWC-CDOP2-GEO-AEMET-SCI-VR-Wind, $37 \mathrm{pp}$. [Available online at http://www.nwcsaf.org/AemetWebContents/ ScientificDocumentation/Documentation/GEO/v2016/NWCCDOP2-GEO-AEMET-SCI-VR-Wind_v1.0.pdf.]

- and R. Borde, 2014: The impact of the tracer size and the temporal gap between images in the extraction of atmospheric motion vectors. J. Atmos. Oceanic Technol., 31, 1761-1770, doi:10.1175/JTECH-D-13-00235.1.

Hautecoeur, O., and R. Borde, 2017: Derivation of wind vectors from AVHRR/MetOp at EUMETSAT. J. Atmos. Oceanic Technol., 34, 1645-1659, doi:10.1175/JTECH-D-16-0087.1.

Hayashi, M., 2012: Recent status and development of atmospheric motion vectors at JMA. Proc. 11th Int. Winds Workshop, Auckland, New Zealand, EUMETSAT, 12 pp. [Available online at http://www.eumetsat.int/website/wcm/ idc/idcplg? IdcService $=$ GET_FILE $\&$ dDocName $=$ PDF $_{-}$ CONF_P60_S1_02_HAYASHI_V\&RevisionSelectionMethod $=$ LatestReleased\&Rendition $=$ Web.]

Holmlund, K., C. S. Velden, and M. Rohn, 2001: Enhanced automated quality control applied to high-density satellite winds. Mon. Wea. Rev., 129, 517-529, doi:10.1175/ 1520-0493(2001)129<0517:EAQCAT > 2.0.CO;2.

Horváth, Á., 2013: Improvements to MISR stereo motion vectors. J. Geophys. Res. Atmos., 118, 5600-5620, doi:10.1002/jgrd.50466. , and R. Davies, 2001: Feasibility and error analysis of cloud motion wind extraction from near-simultaneous multiangle MISR measurements. J. Atmos. Oceanic Technol., 18, 591-608, doi:10.1175/1520-0426(2001)018<0591:FAEAOC >2.0.CO;2.

Key, J., D. Santek, C. S. Velden, N. Bormann, J.-N. Thepaut, L. P. Riishojgaard, Y. Zhu, and W. P. Menzel, 2003: Cloud-drift and water vapor winds in the polar regions from MODIS. IEEE Trans. Geosci. Remote Sens., 41, 482-492, doi:10.1109/ TGRS.2002.808238.

Lazzara, M. A., R. Dworak, D. A. Santek, B. T. Hoover, and C. S. Velden, 2014: High-latitude atmospheric motion vectors from composite satellite data. J. Appl. Meteor. Climatol., 53, 534547, doi:10.1175/JAMC-D-13-0160.1.

Le Marshall, J., N. Pescod, A. Khaw, and G. Allen, 1993: The realtime generation and application of cloud-drift winds in the Australian region. Aust. Meteor. Mag., 42, 89-103. 
Lonitz, K., and Á. Horváth, 2011: Comparison of MISR and $M e$ teosat-9 cloud-motion vectors. J. Geophys. Res., 116, D24202, doi:10.1029/2011JD016047.

Menzel, W. P., W. L. Smith, and T. R. Stewart, 1983: Improved cloud motion wind vector and altitude assignment using VAS. J. Climate Appl. Meteor., 22, 377-384, doi:10.1175/1520-0450 (1983)022<0377:ICMWVA>2.0.CO;2.

Mueller, K. J., C. Moroney, V. Jovanovic, M. J. Garay, J. P. Muller, L. Di Girolamo, and R. Davies, 2013: MISR level 2 cloud product algorithm theoretical basis. JPL Tech. Doc. D-73327, 51 pp. [Available online at http://eospso.nasa.gov/sites/ default/files/atbd/MISR_L2_CLOUD_ATBD-1.pdf.]

— , and Coauthors, 2017: Assessment of MISR cloud motion vectors (CMVs) relative to GOES and MODIS atmospheric motion vectors (AMVs). J. Appl. Meteor. Climatol., 56, 555-572, doi:10.1175/JAMC-D-16-0112.1.

Nieman, S. J., J. Schmetz, and W. P. Menzel, 1993: A comparison of several techniques to assign heights to cloud tracers. J. Appl. Meteor., 32, 1559-1568, doi:10.1175/1520-0450(1993)032<1559: ACOSTT>2.0.CO;2.

Olander, T. L., 2001: UW-CIMSS satellite-derived wind algorithm: User's guide. CIMSS Rep., 83 pp. [Available online at http:// cimss.ssec.wisc.edu/iwwg/Docs/windcoug.pdf.]

Oyama, R., 2010: Recent upgrades of and activities for atmospheric motion vectors at JMA/MSC. Proc. 10th Int. Winds Workshop, Tokyo, Japan, EUMETSAT, 8 pp. [Available online at http:// www.eumetsat.int/website/wcm/idc/idcplg? IdcService $=$ GET FILE\&dDocName $=$ PDF_CONF_P56_S1_01_OYAMA_ $\mathrm{V} \&$ RevisionSelectionMethod $=$ LatestReleased $\&$ Rendition $=$ Web.]

Salonen, K., J. Cotton, N. Bormann, and M. Forsythe, 2015: Characterizing AMV height-assignment error by comparing best-fit pressure statistics from the Met Office and ECMWF data assimilation systems. J. Appl. Meteor. Climatol., 54, 225242, doi:10.1175/JAMC-D-14-0025.1.

Schmetz, J., K. Holmlund, J. Hoffman, B. Strauss, B. Mason, V. Gaertner, A. Koch, and L. Vandeberg, 1993: Operational cloud-motion winds from Meteosat infrared images. J. Appl. Meteor., 32, 1206-1225, doi:10.1175/1520-0450(1993)032<1206: OCMWFM $>2.0 . \mathrm{CO} ; 2$.

Schreiner, A. J., W. P. Menzel, A. Heidinger, J. Davies, and W. Feltz, 2004: Comparison of cloud motion vector height assignment techniques using the GOES-12 imager. Proc. Seventh Int. Winds Workshop, Helsinki, Finland, EUMETSAT, 8 pp. [Available online at http://www.eumetsat.int/ website/wcm/idc/idcplg?IdcService $=$ GET_FILE\&dDocName $=$ PDF_CONF_P42_S3_MENZEL\&RevisionSelectionMethod $=$ LatestReleased\&Rendition $=$ Web.]
Shimoji, K., 2014: Motion tracking and cloud height assignment methods for Himawari-8 AMV. Proc. 12th Int. Winds Workshop, Copenhagen, Denmark, EUMETSAT, 11 pp. [Available online at http://www.eumetsat.int/website/wcm/ idc/idcplg? IdcService $=$ GET_FILE \&dDocName $=$ PDF_ CONF_P61_S2_06_SHIMOJI_V\&RevisionSelectionMethod = LatestReleased\&Rendition $=$ Web.]

Stoffelen, A., K. Atkinson, and A. Regan, 2014: Geometric cloud motion winds in a convoy of satellites. Proc. IEEE Int. Conf. on Geoscience and Remote Sensing Symp., Quebec, Quebec, Canada, Institute of Electrical and Electronics Engineers, TUP.U.144.

Stone, R., P. Pauley, N. Baker, R. Pauley, and B. Karpowicz, 2017: Global AVHRR winds assimilation at Fleet Numerical Meteorology and Oceanography Center/Naval Research Laboratory, Monterey, CA. JCSDA Quarterly, No. 55, Joint Center for Satellite Data Assimilation, College Park, MD, 1-5, doi:10.7289/V5V98648.

Velden, C. S., and K. Holmlund, 1998: Report from the working group on verification and quality indices (WG III). Proc. Fourth Int. Winds Workshop, Saanenmoser, Switzerland, EUMETSAT, 19-20.

— , and K. M. Bedka, 2009: Identifying the uncertainty in determining satellite-derived atmospheric motion vector height attribution. J. Appl. Meteor. Climatol., 48, 450-463, doi:10.1175/2008JAMC1957.1.

_ T. L. Olander, and S. Wanzong, 1998: The impact of multispectral GOES-8 wind information on Atlantic tropical cyclone track forecasts in 1995. Part I: Dataset methodology, description, and case analysis. Mon. Wea. Rev., 126, 12021218, doi:10.1175/1520-0493(1998)126<1202:TIOMGW>2.0. $\mathrm{CO} ; 2$.

Wanzong, S., D. Santek, C. S. Velden, D. Stettner, J. Daniels, W. C. Bresky, and A. Bailey, 2014: Historical GOES AMV re-processing. Proc. 12th Int. Winds Workshop, Copenhagen, Denmark, EUMETSAT, 6 pp. [Available online at http:// www.eumetsat.int $/$ website $/$ wcm/idc/idcplg? IdcService $=$ GET FILE\&dDocName $=$ PDF_CONF_P61_S10_02_WANZONG_ $\mathrm{V} \&$ RevisionSelectionMethod $=$ LatestReleased $\&$ Rendition $=$ Web.]

Warrick, F., 2015: Options for filling the LEO-GEO AMV coverage gap. NWP SAF Tech. Doc. NWPSAF-MO-TR-030, $21 \mathrm{pp}$. [Available online at http://nwpsaf.eu/monitoring/amv/ investigations/gapfill_amvs/nwpsaf_mo_tr_030.pdf.]

_ 2016: NWP SAF AMV monitoring: The 7th analysis report (AR7). NWP SAF Tech. Doc. NWPSAF-MO-TR-032, $35 \mathrm{pp}$. [Available online at http://nwpsaf.eu/monitoring/amv/ nwpsaf_mo_tr_032.pdf.] 